\title{
Numerical investigation and design of aluminium alloy channel section columns at elevated temperatures
}

DOI:

10.1016/j.tws.2020.107225

\section{Document Version}

Accepted author manuscript

Link to publication record in Manchester Research Explorer

\section{Citation for published version (APA):}

Zhu, J., Li, Z., \& Su, M-N. (2020). Numerical investigation and design of aluminium alloy channel section columns at elevated temperatures. Thin-Walled Structures, 107225. https://doi.org/10.1016/j.tws.2020.107225

\section{Published in:}

Thin-Walled Structures

\section{Citing this paper}

Please note that where the full-text provided on Manchester Research Explorer is the Author Accepted Manuscript or Proof version this may differ from the final Published version. If citing, it is advised that you check and use the publisher's definitive version.

\section{General rights}

Copyright and moral rights for the publications made accessible in the Research Explorer are retained by the authors and/or other copyright owners and it is a condition of accessing publications that users recognise and abide by the legal requirements associated with these rights.

\section{Takedown policy}

If you believe that this document breaches copyright please refer to the University of Manchester's Takedown Procedures [http://man.ac.uk/04Y6Bo] or contact uml.scholarlycommunications@manchester.ac.uk providing relevant details, so we can investigate your claim.

\section{OPEN ACCESS}


Ji-Hua Zhu, Zi-qi Li and Mei-Ni Su, (2020) "Numerical investigation and design of aluminium alloy channel section columns at elevated temperatures", Thin-walled Structures, 107225.

\title{
Numerical investigation and design of aluminium alloy channel section columns
}

\section{at elevated temperatures}

\author{
Ji-Hua $\mathrm{Zhu}^{1}, \mathrm{Zi}-\mathrm{qi} \mathrm{Li}^{1}$ and Mei-Ni Su${ }^{2 *}$ \\ ${ }^{1}$ Department of Civil Engineering, Shenzhen University, Shenzhen, China \\ 2 *School of Mechanical, Aerospace and Civil Engineering, University of Manchester, Manchester, UK, \\ email: Meini.su@manchester.ac.uk
}

\section{Abstract}

Aluminium alloys are increasingly popular in structural engineering applications because they have high strength, low weight and great durability. However, the mechanical properties of aluminium alloy material may be significantly affected by high temperature. This paper presents a numerical study on the behaviour of aluminium alloy channel section columns at elevated temperatures. A non-linear finite element (FE) model was developed and validated against 27 experimental results at high temperature. The validated FE model was used to conduct an extensive parametric study, in which a total of 360 aluminium alloy channel section columns were generated at elevated temperatures. The key parameters for the parametric study include two types of aluminium alloys (6061-T6 and 6063-T5), three lengths $(360 \mathrm{~mm}, 1000 \mathrm{~mm}$ and $2000 \mathrm{~mm})$ of columns and ten temperatures (range from $24^{\circ} \mathrm{C}$ to $\left.600^{\circ} \mathrm{C}\right)$. The design strengths were calculated using American, Australia/New Zealand and European Standards and compared with the numerical results generated from parametric study. In addition, a reliability analysis was used to assess the reliability level of the considered design methods.

Keywords: Aluminium alloy; Channel section; Column; Elevated temperatures; Numerical investigation; Structural design 


\section{Introduction}

24 Because of the high strength-to-weight ratio, excellent durability and great anti-corrosion properties, aluminium alloys are widely used in modern structures. The design specifications for aluminium alloy structures, such as the American Aluminium Design Manual (AA) [1], the Australia and New Zealand Standard (AS/NZS) [2], the Eurocode 9 (EC9) [3, 4] and the Chinese Standard (CN) [5], have been published.

encounter during their service life. However, the high temperature properties of aluminium alloys differ from those at room temperature. High temperature significantly affects their mechanical properties due to the low melting point (i.e. around $650^{\circ} \mathrm{C}$ ). For instance, the yield strength of alloy 6061-T6 at $450^{\circ} \mathrm{C}$ decreases to less than $53 \%$ compared to that at room temperature [6]. The significant and necessary to investigate the strength and failure mode of members under elevated temperature conditions, because existing researches on aluminium alloy structures at room temperature cannot be directly applied to the fire design. Since the thermal expansion in aluminium alloys is higher than that of carbon steel, it implies that the thermal strains developed in aluminium alloys would be greater, which would result in larger thermal stresses when members are thermally restrained [7]. For a uniformly heated column without thermal restraint, the effect of heating would result in member elongation. However, the presence of thermal restraint would inhibit the elongation of a compressed member, resulting in development of additional compressive stresses/forces in the member and could result in early failure of the compressed member. 
There have been considerable investigations regarding to aluminium alloy columns at room

temperature. Zhu and Young $[8,9]$ presented test results of aluminium alloy square, rectangular and circular hollow section (SHS, RHS, and CHS, respectively) columns and assessed the accuracy of design rules in the existing specifications. It is shown that the column design strengths predicted by the American, Australian/New Zealand and European specifications are generally conservative. Su et al. [10] carried out a number of stub column experiments on aluminium alloy box sections and found that the continuous strength method (CSM) offered improved design capacities. Wang and Fan [11] presented tests on the stability of aluminium alloy 6082-T6 columns and compared the test strengths with the strength predictions. It found that the AA and EC9 predictions are generally conservative especially for columns with small slenderness ratios, and the AS/NZS predictions are unsafe for more columns. Liu et al. [12] studied the buckling behaviours of complicated section aluminium alloy columns and found that the direct strength method can be more accurate and convenient to predict the ultimate strength of columns under axial compression. Wang et al. [13] investigated the performance of aluminium alloy I-section columns with fixed-end conditions by experiments and numerical simulations and assessed four design standards. It was shown that the design provisions in the above standards provide relatively conservative compressive strength predictions. Su and Young [14] presented tests and numerical simulations of aluminium alloy stocky hollow sections under concentrated transverse loads. These researches have established a good foundation for the study of performance of aluminium alloy members at room temperature. 


84

aluminium alloys at high temperatures. Maljaars et al. $[15,16]$ performed a series of steady and transient state tests on 5083-H111 and 6060-T66 aluminium alloys columns at high temperature and provided simulations of compression tests at high temperature with a finite element (FE) model, which included SHS and angle sections (AS). Afterwards, Maljaars et al. [17] presented a new design method for aluminium columns under fire. Summers et al. [18] presented experiments to investigate the residual mechanical properties of the aluminium alloys AA5083-H116 and AA6061-T651 under fire and established an empirical formula to evaluate the residual yield strength. The evolution models of residual yield strength were established, which can estimate the residual yield strength after a complex thermal exposure, such as in a realistic fire. Jiang et al. [19] presented the experimental and numerical results of CHS and RHS columns under fire conditions and proposed formulae for aluminium alloy columns under fire conditions. It is found that the proposed formulae can provide accurate stability coefficients than existing codes. As an open section, plain and lipped channel sections have better integrity and pleasing line shape, and is easy to connect. It can be used in roof of long-span structure and supporting system of glass curtain wall. However, there is limited experimental or numerical studies on open section columns, such as channel sections, at elevated temperatures. model of aluminium alloy column was established by ABAQUS 6.14 [20] and validated by the collected experimental results. Upon validation, the FE model was used to generate 360 numerical 
results in the parametric study. The design specifications from American, Australia/New Zealand and

Europe were employed to predict the compression strengths and compared with the numerical results.

91 Finally, the reliability levels of the aforementioned design codes were evaluated by reliability analysis.

\section{Summary of the test results}

\subsection{Collected column test results obtained at elevated temperatures}

Maljaars et al. [15] reported both steady and transient state compression tests on an aluminium alloy column exposed to elevated temperature. A series of 27 steady-state test results were collected and used in this paper to validate the newly developed FE model. The steady-state tests were carried out with a constant elevated temperature and a constant strain. In terms of the column tests, firstly, specimens were exposed to a specific temperature before applying loads. The specimens tested at $180^{\circ} \mathrm{C}$ are subjected to $120^{\circ} \mathrm{C}$ for 180 minutes prior to testing. The specimens tested at higher temperatures are subjected to $270^{\circ} \mathrm{C}$ for 30 minutes. Specimens were not restrained during heating. Then, cooling specimen down to ambient temperature and heating of the specimen from ambient to test temperature again within approximately 20 minutes. Similarly, specimens were not restrained during heating. Maintain the test temperature constant for approximately 20 minutes. Finally, apply loads to specimens by strain rate control at $2.5 \times 10^{-3} / \mathrm{min}$ to $7.0 \times 10^{-3} / \mathrm{min}$. The cross-section of the columns included square hollow section (SHS) and angle sections (AS). The columns were extruded by the aluminium alloys 6060-T66 and 5083-H111. For alloy 6060-T66, the flat width (b)-to-thickness $(t)$ ratios $b / t$ equal to 25,44 and 60. For alloy 5083-H111, the $b / t$ ratio equals 50 . 
110 by plates, so there were two longitudinal welds along the specimen. It has been assumed that the

111 welding does not affect the temper or constitutive properties during the test because the plate of alloy

1125083 was already in soft temper [15]. The length $(L)$ of all specimens was $300 \mathrm{~mm}$. The test

113 temperatures ranged from $20^{\circ} \mathrm{C}$ to $400^{\circ} \mathrm{C}$. The details of the dimensions, test setup and material

114 properties can be found in [15]. The ultimate strengths of test columns $\left(P_{\exp }\right)$ are shown in Table 1.

\subsection{Collected tensile coupon test results}

117 This paper also collected the experimental results reported by $\mathrm{Su}$ and Young [6] regarding to the 118 material properties of the aluminium alloys 6061-T6 and 6063-T5 at high temperature. The results of 11915 steady-state coupon tests were collected and used in this paper. During testing, the specimen was 120 heated to the specified temperature, and then loaded until it failed. The specimens were loaded at 10 121 different nominal temperatures of $24,100,200,250,300,350,400,450,500$ and $600^{\circ} \mathrm{C}$, respectively. 122 During the experiment, the upper end of the specimens was clamped, and the lower end expanded 123 freely during heating until the required temperature was reached. The temperature rate is $15^{\circ} \mathrm{C} / \mathrm{min}$. 124 After stabilizing the required temperature for ten minutes, the lower end of the coupon specimen was clamped for tensile test. Tensile load was applied to the specimen by displacement control at 0.3 $\mathrm{mm} / \mathrm{min}$. The duration of each specimen is different, ranging from 40 minutes to 120 minutes. The material properties at high temperature are shown in Table 2 for aluminium alloy 6061-T6 and Table 3

128 for aluminium alloy 6063-T5. The full stress-strain curves of both alloys at elevated temperatures are presented in Ref [6]. 


\section{Numerical study}

132 A FE software ABAQUS [20] was used to carry out numerical modelling in this study. The 133 developed FE model was validated by 27 steady-state compression test results [15]. Upon validation, 134 a parametric study on the performance of aluminium alloy channel section columns at high 135 temperatures was carried out, and 360 numerical results were generated.

\subsection{Finite element modelling}

138 A reliable and accurate non-linear FE model for aluminium alloy channel columns at room 139 temperature was developed and validated by Zhu et al. [21]. In this paper, the FE model was revised 140 for modelling columns at high temperature. The FE modelling comprised two steps: first, obtain the 141 eigenvalue buckling modes of a column without imperfection by elastic buckling analysis; secondly, conduct non-linear analysis to obtain the ultimate load capacity and failure mode of column

143 incorporated with imperfection. Two types of geometric imperfections were considered in the FE 144 model. The magnitude of the local imperfection was taken as $10 \%$ of the element thickness, and the 145 magnitude of the overall imperfection was chosen as 1/2000 of the column length. Zhu et al. [21] 146 have conducted experimental studies on channel section columns at room temperature; the failure 147 modes observed include local buckling, the interaction of local and flexural buckling, and a 148 combination of local, flexural, and flexural-torsional buckling [1]. Distortional buckling was not 149 observed in experiments conducted at room temperature. Therefore, the distortional mode is not considered as the initial geometric imperfection. The FE model employed the S4R shell elements. The element size of all columns was $5 \mathrm{~mm} \times 5 \mathrm{~mm}$. The measured cross-sectional dimensions and material 
152 properties of specimens at high temperature, reported by Maljaars et al. [15], were incorporated in the

153 FE model. The boundary conditions of the fixed ends were simulated by constraining the degrees of

154 freedom of the nodes at both ends except the translational degree of freedom at one end of the column 155 in the axial direction.

In finite element modelling, true stress-strain curves are used. In the non-linear analysis stage, material non-linearity or plasticity was included in the FE model using a mathematical model known as the incremental plasticity model, in which true stresses $\left(\sigma_{\text {true }}\right)$ and true plastic strains $\left(\varepsilon_{\text {true }}^{\mathrm{pl}}\right)$ were specified. The true stresses and true plastic strains were obtained from the static engineering stresses

$160(\sigma)$ and strains $(\varepsilon)$ using Eqs. (1) and (2) as specified in the FE model, where $E$ is the initial 161 Young's modulus of the static engineering stress-strain curve.

$$
\varepsilon_{\text {true }}^{\mathrm{pl}}=\ln (1+\varepsilon)-\sigma_{\text {true }} / E
$$

\subsection{Model validation}

The numerical results were compared to a total of 27 steady-state compression test results [15], as shown in Table 1. According to the results, the ultimate strengths obtained from the FE model were close to the ultimate loads obtained from experiments. The average value of the ultimate load ratio $P_{E x p} / P_{F E}$ between the experiment and the FE analysis is 0.99 , and the corresponding coefficient of variation $(\mathrm{CoV})$ is 0.083 . The comparisons of typical failure modes from the experiments and numerical simulations of the column are shown in Fig. 1. The curves of the load-displacement of typical columns from the FE model are plotted and compared with the experimental curves, as shown 
173 in Fig. 2. The results show that the FE model could accurately predict the ultimate load capacities 174 and loading behaviours of the test columns at high temperature. Thus, the FE model has been 175 validated by Channel section column tests at room temperature [21] as well as SHS and Angle 176 section column tests at elevated temperatures [15], since the Channel section column test result at 177 elevated temperatures is not available.

\subsection{Parametric study}

The FE model accurately predicted the ultimate load capacities as well as the type of failure modes of columns tested by Maljaars et al. [15]. Hence, an extensive parametric study was conducted to study the influences of key parameters on the structural responses of channel section columns at elevated temperatures. The parametric study generated a total of 360 numerical results covering high-strength (6061-T6) and normal-strength (6063-T5) aluminium alloys. The material properties of these two alloys at elevated temperatures can be found in the literature [6], as shown in Tables 2-3. The parametric study considered both plain and lipped channel sections. In parametric study, the boundary conditions were set as fixed-ended. The fixed-ended boundary condition was simulated by restraining all the degrees of freedom of the nodes at both ends, except for the translational degree of freedom in the axial direction at one end of the column. The nodes other than the two ends were free to translate and rotate in any directions. The considered temperatures were $24,100,200,250,300,350$, $400,450,500$ and $600^{\circ} \mathrm{C}$, and the effective lengths included 360,1000 and $2000 \mathrm{~mm}$. There was no weld in the modelled specimens and residual stress was not incorporated because it has little effect on the extruded aluminum alloy members [22]. The dimensions of the channel sections are shown in 
Table 4, where $H, B, B_{l}, t$ are the depth of the cross section, width of the cross section, stiffener length and thickness of the cross section, respectively, as shown in Fig. 3. The specimens were labelled to identify the type of aluminium alloy, the type of section, the column length and the temperature. For instance, the label "H-P1-L360-T100" defines the following specimen:

- The first part shows the type of alloy of the column. " $\mathrm{H}$ " indicates the aluminium alloy 6061-T6 and "N" indicates the aluminium alloy 6063-T5.

- The next part of the label shows the type of section, where "P" refers to the plain channel section, and "L" refers to the lipped channel section. The detailed cross-sectional dimensions of the specimen are shown in Table 4.

- The third part of the label shows the nominal length of the column, where "L360" means that the specimen nominal length is $360 \mathrm{~mm}$.

- The last part of the label "T100" means that the environment temperature is $100^{\circ} \mathrm{C}$.

The ultimate strengths of columns at elevated temperatures from the parametric study are presented in Tables 5-8 and Fig. 4, together with the classification of cross-sections and section slenderness ratio $(H / t, \mathrm{~B} / \mathrm{t})$. It can be concluded from the parametric study results that a significant decrease in the load capacities can be observed from $300^{\circ} \mathrm{C}$ to $600^{\circ} \mathrm{C}$ for the aluminium alloy $6061-\mathrm{T} 6$ columns, while for the aluminium alloy 6063-T5 specimens, the reduction in ultimate strengths is generally consistent from $100^{\circ} \mathrm{C}$ to $600^{\circ} \mathrm{C}$.

The columns modelled in the parametric study showed several different failure modes (see Fig.5).

15 For plain channel section columns, the failure mode of the short column was local buckling, the 
medium-long columns failed by a combination of local and flexural buckling and the long columns

217 failed by flexural buckling. For lipped channel section columns, the short columns failed by local

218 buckling and the medium-long columns failed by local and flexural buckling, which are similar to 219 plain channel section columns. The failure modes of long columns included flexural bucking and 220 flexural-torsional buckling.

\section{Comparisons with the design methods}

223 A total of 360 numerical results generated from parametric study were compared with the design 224 strengths predicted by the AA [1], AS/NZS [2] and EC9 [4] standards.

\subsection{Aluminium Design Manual}

The column strength prediction at ambient temperature of the AA specification $\left(P_{A A}\right)$ uses the lowest of the available strengths for the limit states of member buckling $\left(P_{n c 1}\right)$, local buckling $\left(P_{n c 2}\right)$, and the interaction between member buckling and local buckling $\left(P_{n c 3}\right)$. This is determined as shown in Eq. (3), while detailed calculation steps have summarized by Zhu et al. [20]:

$$
P_{A A}=\min \left(P_{n c 1}, P_{n c 2}, P_{n c 3}\right)
$$

The AA [1] calculates the load capacity of members at high temperatures by reducing the mechanical properties of aluminium alloy obtained from ambient temperature. The reduction factor

234 of the elasticity modulus for all 6XXX series alloys is the same, whereas the reduction factors of the 235 yield and ultimate strengths at elevated temperatures are different for alloys 6061-T6 and 6063-T5. 
The detailed reduction factor can be found in Part 1 of the AA [1]. The material properties at high temperatures reduced according to the codified factor in AA is shown in Tables 2-3. In this study,

238 both the measured material properties by tensile coupon tests at elevated temperatures and the codified 239 material properties in AA were used for calculation, and the corresponding design strengths were 240 indicated by $P_{A A-1}$ and $P_{A A-2}$, respectively.

\subsection{Australian/New Zealand Standard}

243 The design approach in the AS/NZS [2] $\left(P_{A S / N A S-1}\right)$ is similar to the AA specification, as shown in 244 Section 3.4.8 [2]. The material properties used for the calculation were measured at elevated temperatures, since the AS/NZS does not provide recommended material properties at high temperatures.

\subsection{Eurocode 9}

According to the Eurocode 9 [3], under the axial compression loading, structure members could fail by flexural, torsional or flexural torsional and local squashing. Effective cross-section method is used to calculate the compression section capacity. The design rule strength $\left(P_{E C 9}\right)$ in the Eurocode 9 [3] of compression members at room temperature is the minimum value of design resistance $\left(P_{c, R d}\right)$ and design buckling resistance $\left(P_{b, R d}\right)$, while detailed calculation steps have summarized by Zhu et al. 254 [21]:

$$
P_{E C 9}=\min \left(P_{c, R d}, P_{b, R d}\right)
$$

The reduction factor of the yield strengths and modulus of elasticity are shown in Chapter 3.2 of 
257 Eurocode 9 [4], while the design procedure is presented in Eurocode 9 [3]. The residual material 258 properties at high temperatures were calculated and shown in Tables 2-3. The material properties 259 used for the calculation were taken as the measured material properties at high temperatures for $P_{E C 9-1}$ 260 and the measured room temperature properties multiplied by codified reduction factors for $P_{E C 9-2}$.

\subsection{Result comparisons}

263 The ultimate strengths of the aluminium alloy channel column at elevated temperatures were predicted by the AA [1], AS/NZS [2] and EC9 [3, 4] specifications. The predicted strengths were compared with the numerical results obtained from the parametric study. The comparisons of the results are summarised in Fig. 6, as well as Tables 9-12. In the comparison, all partial safety factors are set to be the unity.

For high strength aluminium alloy columns (Series H-P and H-L), the predictions from the AA standard with the measured material properties are the most accurate and consistent among all design methods, i.e., the mean values of the load ratio $P_{F E} / P_{A A-1}$ are found to be 1.00 and 1.07 with CoVs of 0.070 and 0.048 , respectively. In terms of the AS/NZS specification predictions with measured material properties, the mean values of the load ratio $P_{F E} / P_{A S / N A S-1}$ are 1.04 and 1.12 with CoVs of 0.104 and 0.082 , respectively, which are also rather accurate. The predictions from EC9 with the measured material properties are slightly conservative, i.e., the mean values of the load ratio $P_{F E} / P_{E C 9-1}$ are 1.12 and 1.26 with CoVs of 0.060 and 0.089 , respectively. However, the predictions of 
especially after $250^{\circ} \mathrm{C}$. The reason is mainly attributed to the inaccurate reduction in the material properties. The mean values of $P_{F E} / P_{A A-2}$ for plain and lipped channel sections are up to 6.26 and 6.86 with CoVs of 1.067 and 1.049 , respectively. Similarly, the mean values of the load ratio $P_{F E} / P_{E C 9-2}$ for plain and lipped channel sections are 5.48 and 6.05 with CoVs of 0.907 and 0.885 , respectively. Based on the results, it is found that when using the measured material properties, all the three design standards show high accuracy and consistency with the AA being the best.

Regarding to the normal strength aluminium alloy columns (Series N-P and N-L), the accuracy and consistency of the predicted results are much higher by substituting the measured material properties at high temperature into the AA, AS/NZS and EC9 standards. When using the measured material properties, the predictions by the AA are the most accurate, i.e., the mean values of the load ratio $P_{F E} / P_{A A-1}$ are 1.01 and 1.08 with CoVs of 0.066 and 0.049 , respectively, followed by the AS/NZS and EC9. For plain channel section, EC9 provides most consistent prediction, while for lipped channel sections, the AA is more consistent than the other two standards. Similar to the high strength aluminium alloy columns, when using the codified properties of the material, the accuracy and consistency of the design strengths by the AA and EC9 are decreased - the mean values of the load ratio $P_{F E} / P_{A A-2}$ are 3.22 and 3.48 for plain and lipped channel sections with CoVs being 0.631 and 0.621 , respectively; the mean values of the load ratio $P_{F E} / P_{E C 9-2}$ for plain and lipped channel sections are 2.29 and 2.61 with CoVs of 0.472 and 0.448 , respectively. 


\section{Reliability analyses}

299 Reliability analyses were employed to evaluate the reliability levels of the design codes in this study.

300 The safety level of the design method can be reasonably measured by the reliability index $(\beta)$. In the

301 AA [1], AS/NZS [2] and Eurocode 9 [3, 4], the target index $\beta$ of aluminium alloy structural 302 component design is set to be 2.5 . If the derived reliability index is greater than 2.5 , the design codes 303 are considered to be safe. The design load combinations applied in the reliability analysis are 304 1.2D+1.6L for AA [1], 1.25D+1.5L for AS/NZS [2], 1.35D+1.5L for EC9 [3, 4], where "D" and "L" 305 indicate the dead and live loads, respectively. The codified resistance factors $(\phi)$ of the AA, AS/NZS and EC9 are 0.85, 0.85 and 0.91, respectively.

The reliability index $\beta$ of all design codes for the four series of specimens are shown in Tables

9-12. For high strength aluminium alloy plain channel section columns (Series H-P), the reliability indexes of the AA and EC9 using the codified material properties are found to be less than the target value of 2.50. All predicted reliability indexes of the three design methods using measured material properties are higher than the target reliability index of 2.50. For high strength aluminium alloy lipped channel section columns (Series H-L), the reliability index $\beta$ of all the design codes are greater than 2.50, except for AA approach using the codified material properties. For normal strength aluminium alloy columns (Series N-P and N-L), the reliability indices of all design rules are found to be higher than the target reliability index. To summarize, when using the measured material properties at elevated temperatures, the existing design methods in the AA, AS/NZS and EC9 are rather reliable for column design at high temperatures. 


\section{Conclusions}

321 This paper investigated the behaviour and design of aluminium alloy channel columns at elevated

322 temperatures. The FE model developed by ABAQUS was validated by experimental data from 323 Maljaars et al. [15]. The validated FE model was employed for a parametric study considering 324 aluminium alloy columns of both plain channel and lipped channel sections at high temperatures. 325 The parametric study generated a total of 360 numerical results. Both high and normal strength 326 aluminium alloys (6061-T6 and 6063-T5, respectively) were considered. The material properties of 327 the two alloys were reported by $\mathrm{Su}$ and Young [6] and used in this study. The temperatures 328 considered in the study covered a wide range including $24,100,200,250,300,350,400,450,500$ 329 and $600^{\circ} \mathrm{C}$. The capacities of the columns obtained by the numerical investigation were compared 330 with the compressive strengths predicted by the existing American, Australian/New Zealand and 331 European standards for aluminium structures. In general, the ultimate strengths predicted by the 332 considered design methods were rather accurate when employing the measured material properties; 333 however, the predictions could be significantly scattered and inaccurate if the codified material 334 properties were adopted in the design. Therefore, the existing design methods for columns at ambient temperature are applicable to columns at elevated temperatures provided that accurate material properties are available and used. The reliability of the three considered standards for channel columns at elevated temperatures was assessed by reliability analysis. The results show that all the design rules using the measured material properties are reliable for the design of aluminium alloy channel columns at elevated temperatures. 


\section{Acknowledgements}

343 The research work described in this paper was supported by the National Natural Science Foundation 344 China (51778370, 51538007), the Key Project of Department of Education of Guangdong Province 345 (2017B030311004) and the Shenzhen science and technology project (JCYJ20170818094820689).

\section{Notations}

\begin{tabular}{|c|c|c|}
\hline 347 & $b$ & flat width \\
\hline 348 & $B$ & section width \\
\hline 349 & $B_{l}$ & stiffener length of section \\
\hline 350 & $E_{T}$ & Young's modulus at elevated temperature \\
\hline 351 & $f_{u, T}$ & ultimate stress at elevated temperature \\
\hline 352 & $f_{y, T}$ & $0.2 \%$ proof stress at elevated temperature \\
\hline 353 & $H$ & section depth \\
\hline 354 & $L$ & column length \\
\hline 355 & $P_{A A}$ & design strengths from AA standard at ambient temperature \\
\hline 356 & $P_{A A-1}$ & design strengths from AA standard using measured material properties \\
\hline 357 & $P_{A A-2}$ & design strengths from AA standard using codified material properties \\
\hline 358 & $P_{A S / N Z S-1}$ & design strengths by the AS/NZS using measured material properties \\
\hline 359 & $P_{b, R d}$ & design buckling resistance of the compression member by the EC9 \\
\hline 360 & $P_{c, R d}$ & design resistance to normal forces of the cross-section for uniform compression by the EC9 \\
\hline 361 & $P_{E C 9}$ & design strengths from EC9 at ambient temperature \\
\hline 362 & $P_{E C 9-1}$ & design strengths from EC9 using measured material properties \\
\hline 363 & $P_{E C 9-2}$ & design strengths from EC9 using codified material properties \\
\hline
\end{tabular}


$364 \quad P_{F E} \quad$ ultimate loads obtained from the FE model

$365 \quad P_{n c 1} \quad$ member buckling strength from AA

$366 P_{n c 2} \quad$ local buckling strength from AA

$367 \quad P_{n c 3} \quad$ interaction between member buckling and local buckling from AA

$368 \quad P_{u} \quad$ experimental ultimate loads

$369 t \quad$ thickness of the section

$370 \quad \beta \quad$ reliability index

$371 \phi \quad$ resistance factor 


\section{References}

[1] Aluminium Association, Aluminium Design Manual, The Aluminium Association, Washington, DC, 2015.

[2] AS/NZS, Aluminium Structures-Part 1: Limit State Design, Australian/New Zealand Standard AS/NZS1664.1:1997. Sydney, Australia: Standards Australia,1997

[3] European Committee for Standardization (EC9), EUROCODE 9: Design of Aluminium Structures-Part 1-1: General Rules and Rules for Buildings, BS EN 1999-1-1:2007, CEN, 2007.

[4] European Committee for Standardization (EC9), EUROCODE 9: Design of Aluminium Structures-Part 1-2: Structural fire design, BS EN 1999-1-2:2007, CEN, 2007.

[5] CN. Code for design of aluminium structures. Ministry of Construction of the People's Republic of China. GB50429-2007.

[6] Su, M. N., Young B., "Material Properties of Normal and High Strength Aluminium Alloys at Elevated Temperatures". Thin-walled Structures, in press.

[7] Neves I C, Valente J C, Rodrigues J P C. Thermal restraint and fire resistance of columns. Fire Safety Journal, 2002, 37(8):753-771.

[8] Zhu, J.H., Young, B. "Tests and Design of Aluminum Alloy Compression Members", J. Struct. Eng. ASCE 132 (7) (2006) 1096-1107.

[9] Zhu J H, Young B. "Experimental investigation of Aluminum Circular Hollow Section Columns". Engineering Structures, 2006,28(2):207 215

[10] Su M N, Young B, Gardner L. "Testing and Design of Aluminum Alloy Cross Sections in Compression”. Journal of Structural Engineering, 2014, 140(9):04014047.

[11] Wang Y, Fan F, Lin S. "Experimental investigation on the stability of aluminium alloy 6082 
circular tubes in axial compression”. Thin-Walled Structures, 2015, 89:54-66.

[12]Liu M, Zhang L, Wang P, et al. "Buckling behaviors of section aluminum alloy columns under axial compression”. Engineering Structures, 2015, 95:127-137.

[13] Wang Y Q, Yuan H X, Chang T, et al. "Compressive buckling strength of extruded aluminium alloy I-section columns with fixed-pinned end conditions”. Thin-Walled Structures, 2017, 119:396-403.

[14] Su M N, Young B. "Design of aluminium alloy stocky hollow sections subjected to concentrated transverse loads". Thin-Walled Structures, 2018, 124:546-557.

[15]Maljaars J, Soetens F, Snijder H H. “Local buckling of aluminium structures exposed to fire. Part 1: Tests”. Thin-Walled Structures, 2009, 47(11):1404-1417.

[16]Maljaars J, Soetens F, Snijder H H. "Local buckling of aluminium structures exposed to fire: Part 2: Finite element models". Steel Construction, 2009, 47(11):1418-1428.

[17]Maljaars J J, Twilt L L, Soetens F F. “Flexural buckling of fire exposed aluminium columns”. Fire Safety Journal, 2009, 44(5):711-717.

[18] Summers P T, Case S W, Lattimer B Y. "Residual mechanical properties of aluminum alloys AA5083-H116 and AA6061-T651 after fire”. Engineering Structures, 2014, 76:49-61.

[19]Jiang S, Xiong Z, Guo X, et al. "Buckling behaviour of aluminium alloy columns under fire conditions". Thin-Walled Structures, 2018, 124:523-537.

[20]ABAQUS Analysis User's Manual, version 6.14, ABAQUS Inc., 2014.

[21]Zhu, J.H., Li, Z, Q., Su, M.N., Young, B., "Behaviour of Aluminium Alloys Plain and Lipped Channel Columns", Thin-Walled Structures, 2019, 135:306-316.

[21] Mazzolani FM. Aluminium alloy structures. 2nd ed. E\&FN Spon Press;1995 

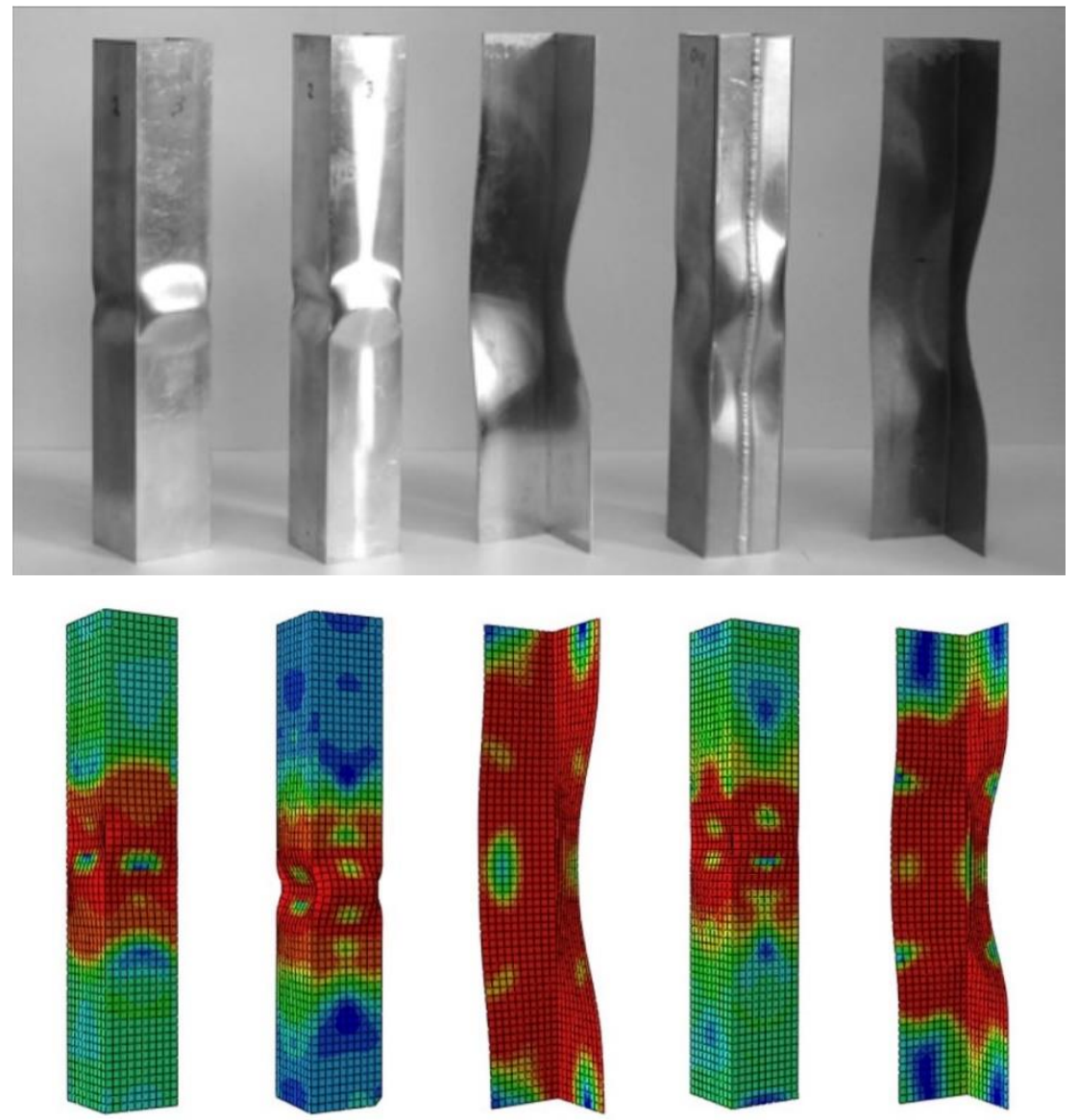

(a) 1-2

(b) T9-1

(c) TA7

(d) $\mathrm{O} 6$

(e) $\mathrm{OA} 3$

Fig.1. Typical failure modes of the test specimens and the FE models 420 


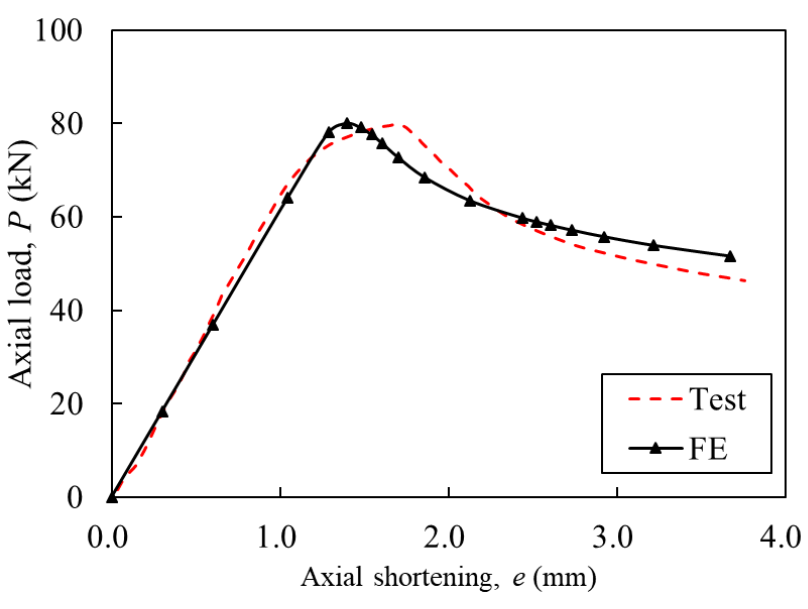

(a) Specimen 2-2

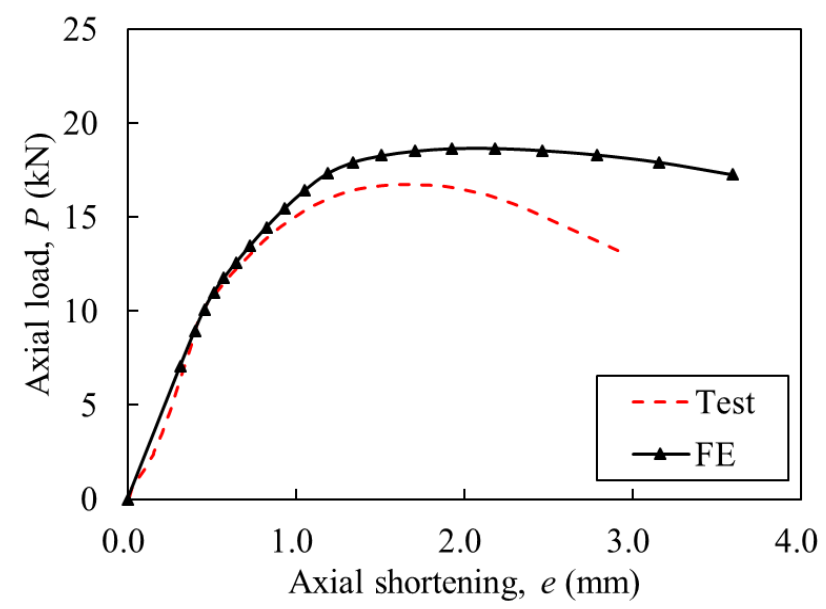

(c) Specimen TA11

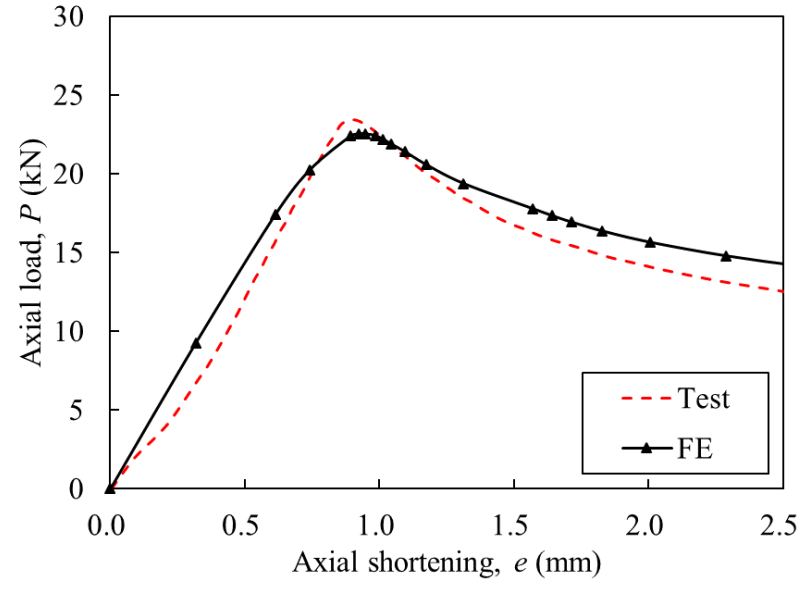

(b) Specimen T4-1

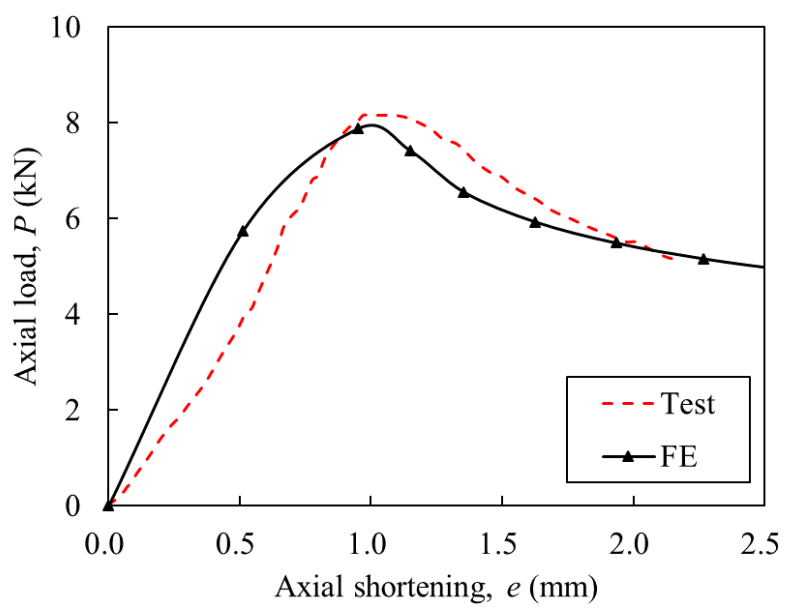

(d) Specimen $\mathrm{O} 3$

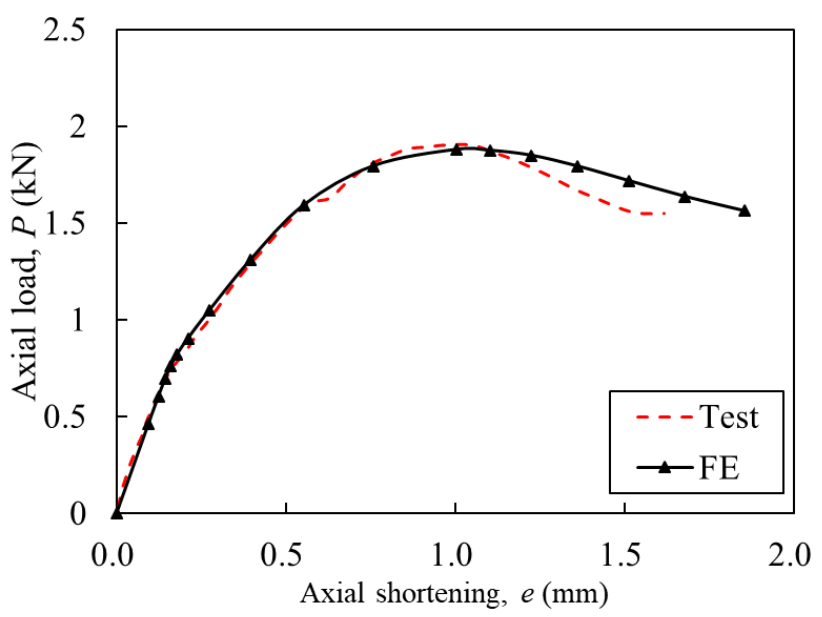

(e) Specimen OA6

Fig. 2. Comparisons of the experimental and numerical load-deformation curves 

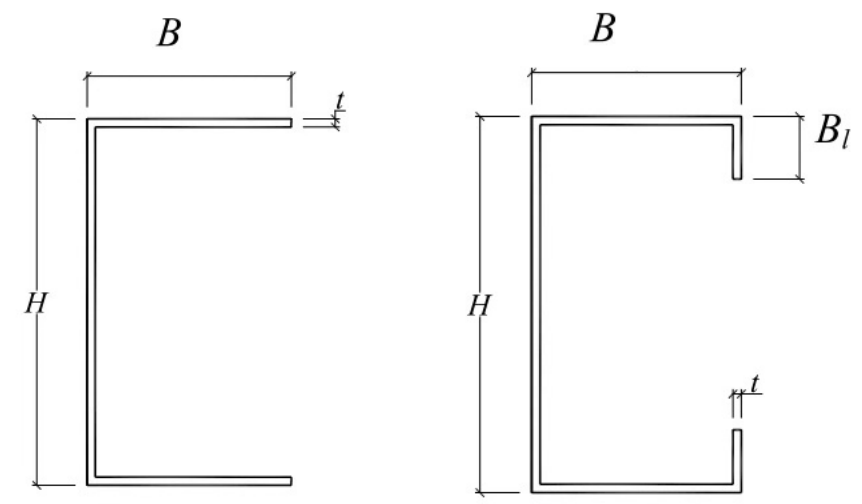

Fig. 3. Definition of symbols for cross-sections 


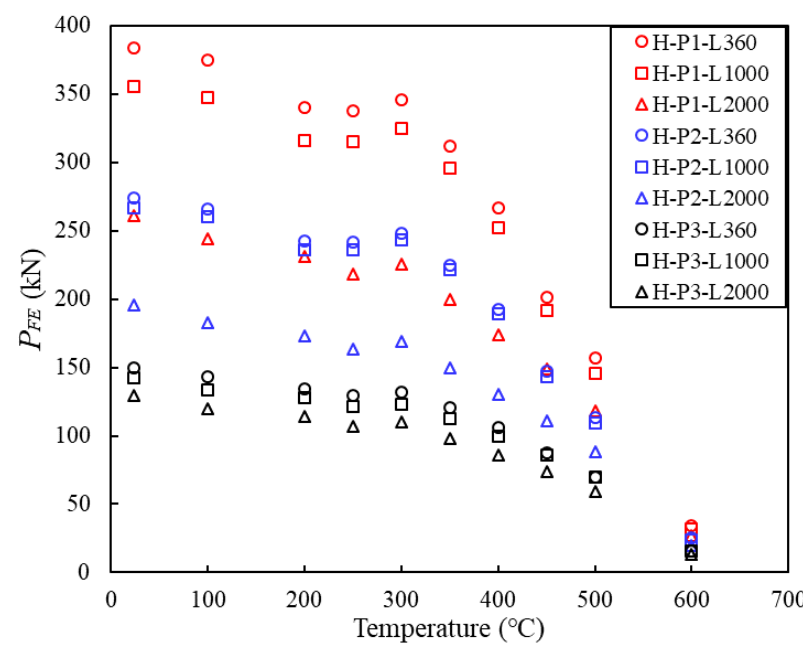

(a) Series H-P

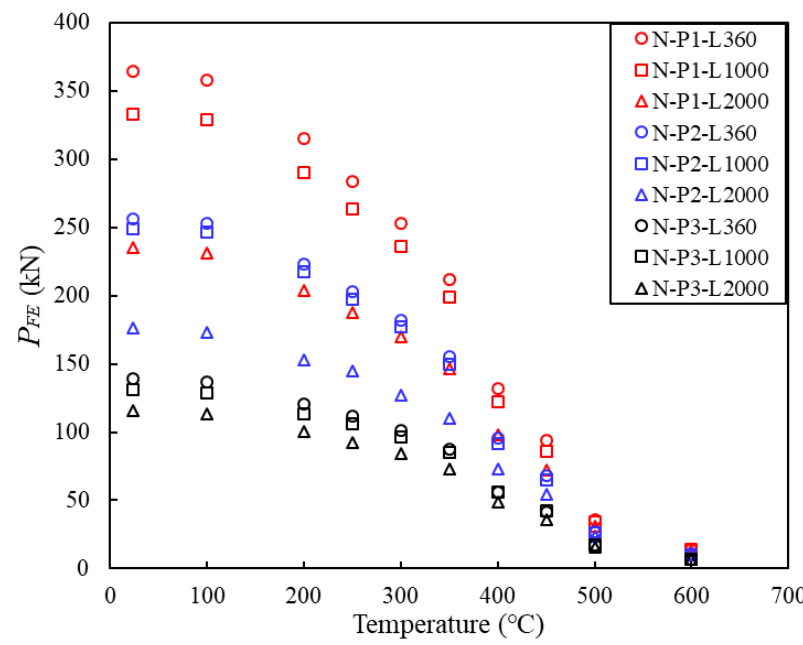

(c) Series N-P

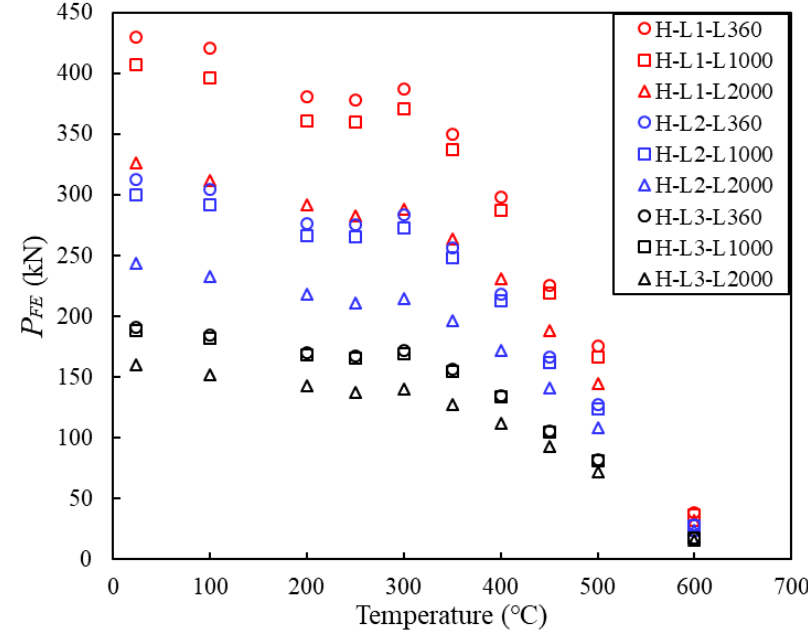

(b) Series H-L

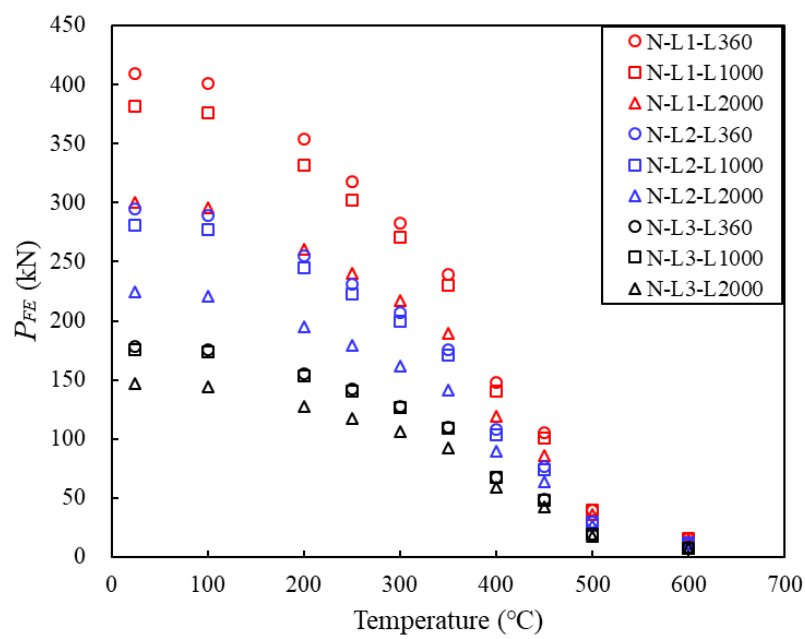

(d) Series N-L

Fig. 4. Numerical ultimate strengths of FE model at elevated temperatures 


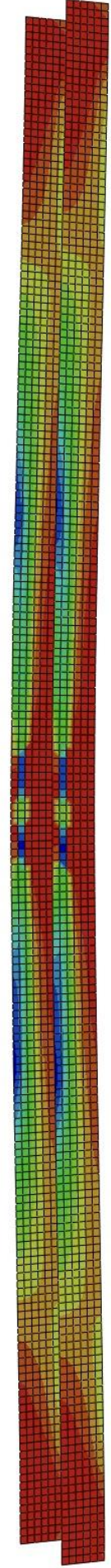

(c)

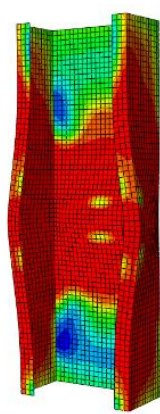

(d)

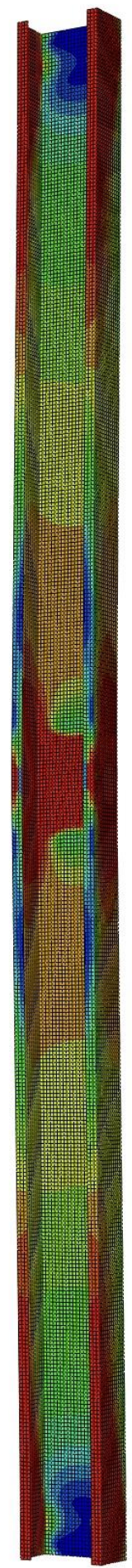

(f)

[i] plain channel section

[ii] lipped channel section

Fig. 5. Failure modes of specimens in the parametric study. (a) H-P2-L360-T300 (b) H-P2-L1000-T300 (c) H-P2-L2000-T300 (d) H-L2-L360-T300 (e) H-L2-L1000-T300 (f) H-L3-L2000-T300 


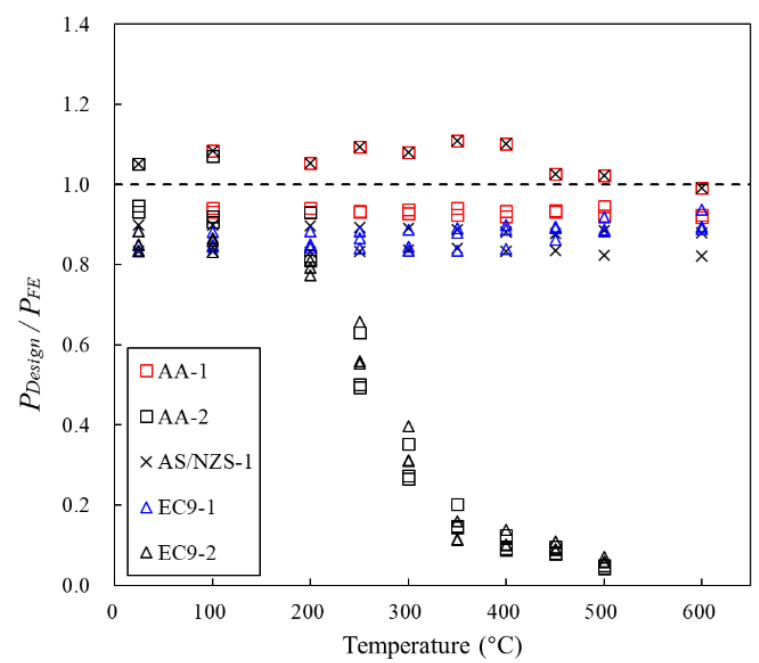

(a) Series H-P1

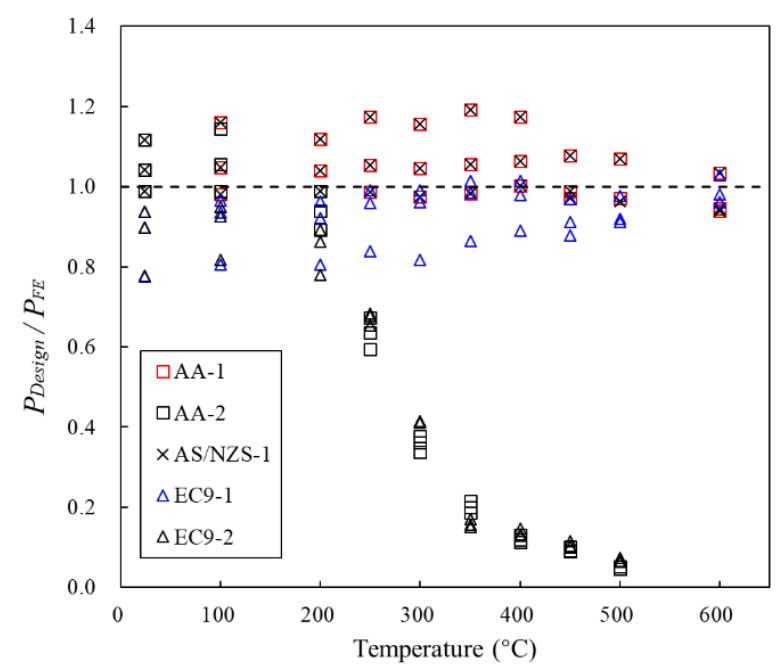

(c) Series H-P3

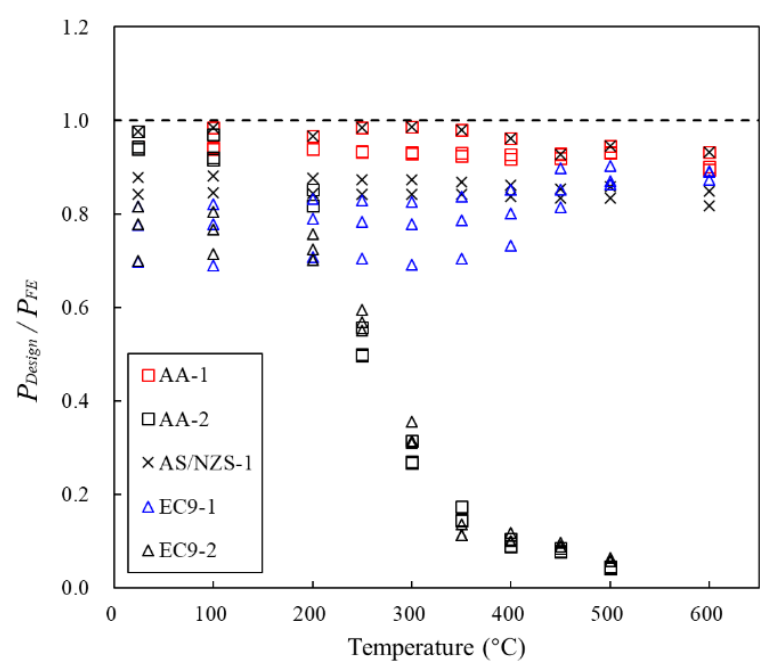

(e) Series H-L2

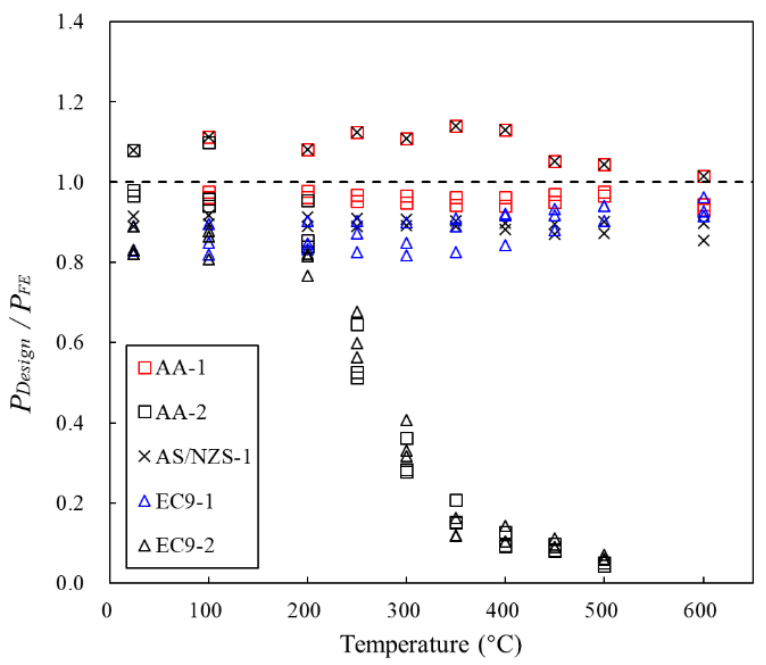

(b) Series H-P2

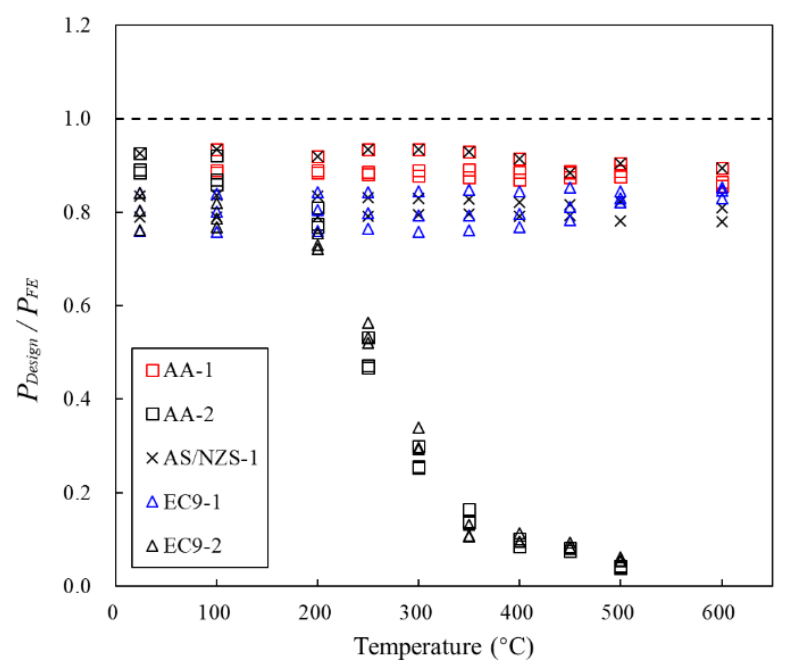

(d) Series H-L1

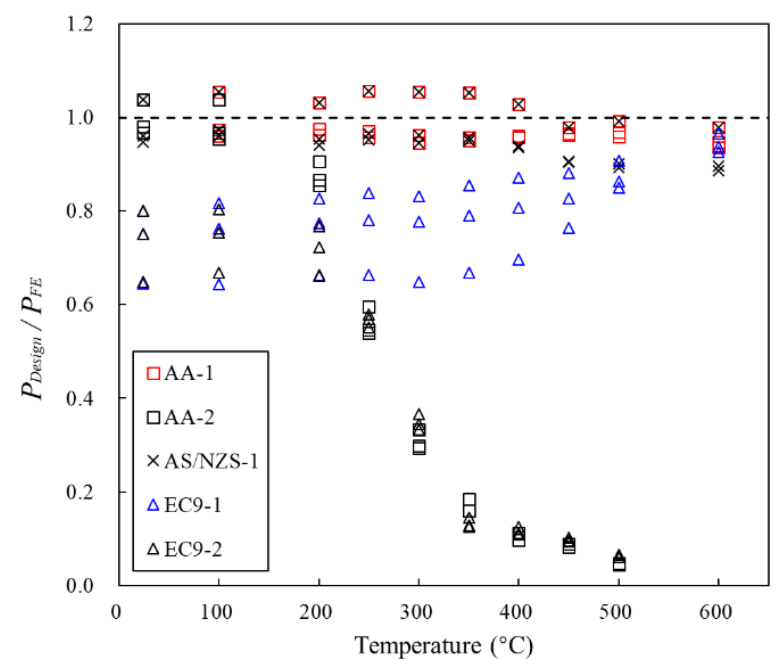

(f) Series H-L3 


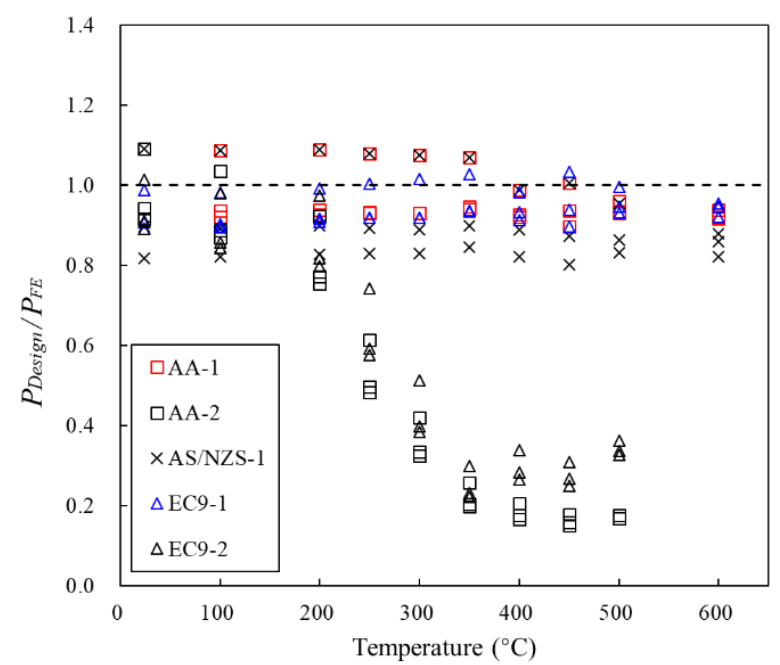

(g) Series N-P1

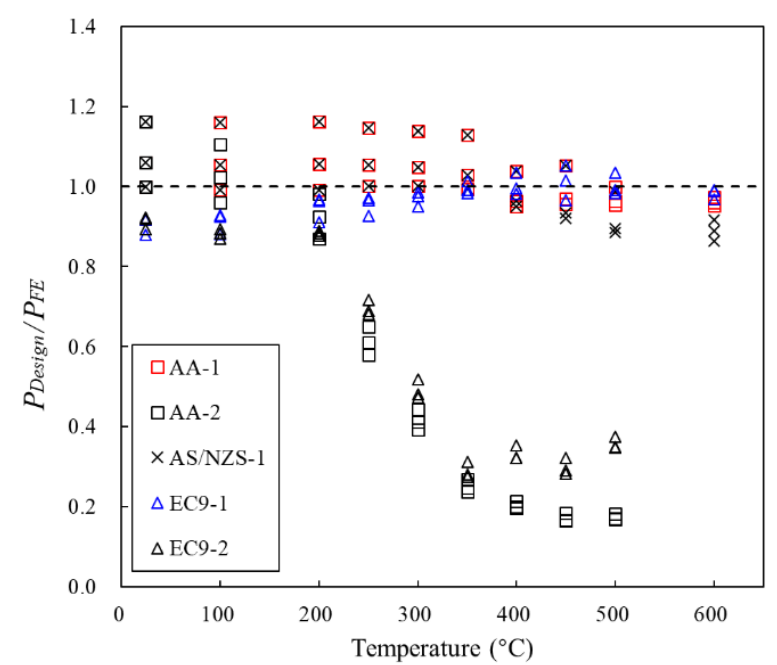

(i) Series N-P3

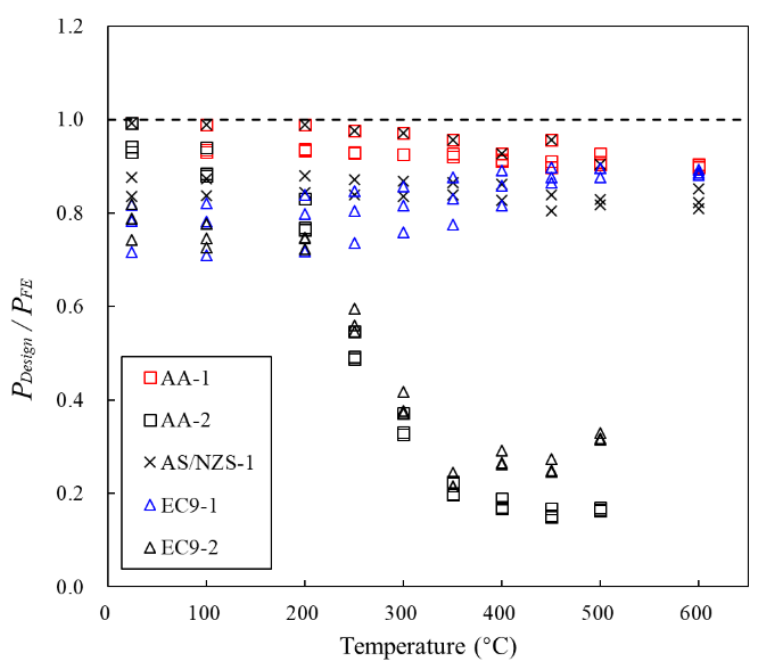

(k) Series N-L2

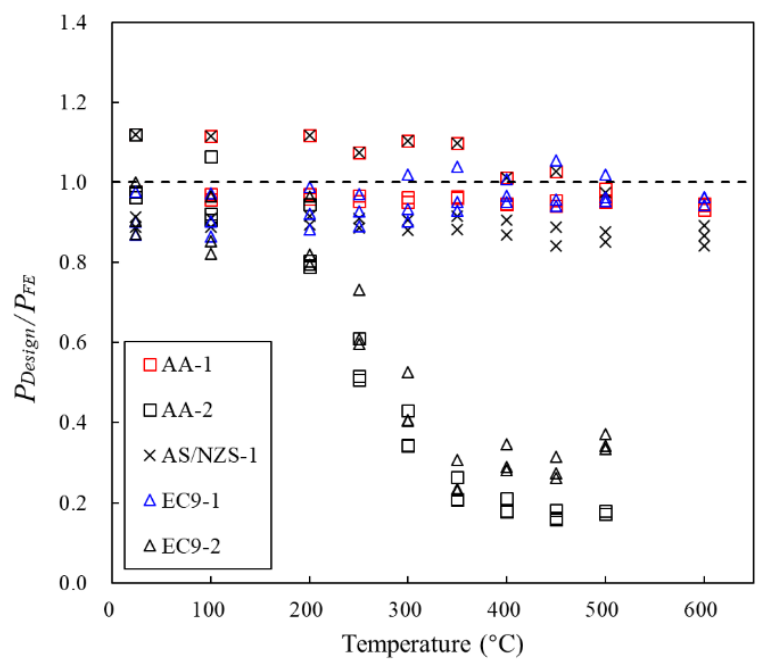

(h) Series N-P2

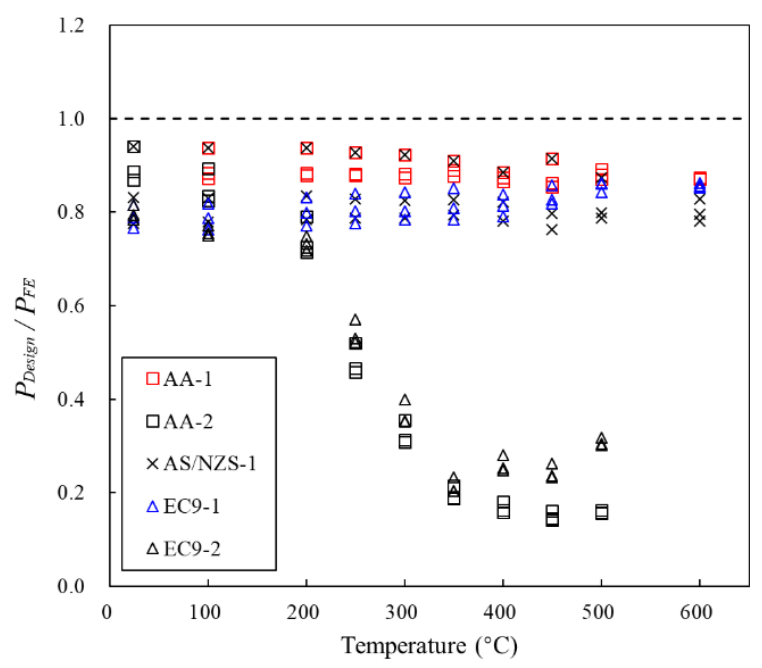

(j) Series N-L1

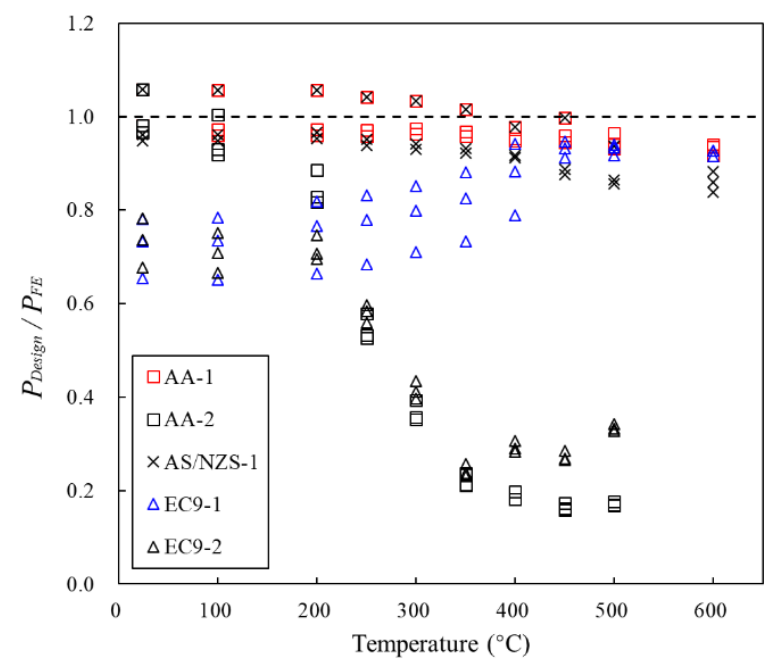

(1) Series N-L3

Fig. 6. Comparison of the design predictions with numerical ultimate strengths 
Table. 1. Comparison of test results [15] and FE results

\begin{tabular}{|c|c|c|c|c|c|c|c|c|}
\hline Specimens & $\begin{array}{c}\text { Type of } \\
\text { Cross-section }\end{array}$ & $\begin{array}{l}\text { Type of } \\
\text { Material }\end{array}$ & $\begin{array}{c}b \\
(\mathrm{~mm})\end{array}$ & $\begin{array}{c}t \\
(\mathrm{~mm})\end{array}$ & $\begin{array}{c}\text { Test } \\
\text { Temperature } \\
\left({ }^{\circ} \mathrm{C}\right) \\
\end{array}$ & $\begin{array}{r}P_{E x p} \\
(\mathrm{kN})\end{array}$ & $\begin{array}{c}P_{F E} \\
(\mathrm{kN})\end{array}$ & $P_{E x p} / P_{F E}$ \\
\hline $1-2$ & SHS & 6060-T66 & 50 & 2 & 20 & 78.8 & 80.3 & 0.98 \\
\hline $2-2$ & SHS & 6060-T66 & 50 & 2 & 20 & 79.1 & 80.0 & 0.99 \\
\hline T4-2 & SHS & 6060-Т66 & 50 & 2 & 20 & 81.0 & 84.3 & 0.96 \\
\hline T5-2 & $\mathrm{SH}$ & 6060-Т66 & 50 & 2 & 179 & 65.8 & 58.7 & 1.12 \\
\hline T3-2 & SHS & 6060-Т66 & 50 & 2 & 265 & 28.8 & 27.1 & 1.06 \\
\hline $\mathrm{T} 2-2$ & SHS & 6060-Т66 & 50 & 2 & 290 & 22.7 & 22.6 & 1.00 \\
\hline T9-1 & SHS & 6060-Т66 & 48.2 & 1.1 & 20 & 26.8 & 29.2 & 0.92 \\
\hline T4-1 & SHS & 6060-T66 & 48.2 & 1.1 & 179 & 23.4 & 22.5 & 1.04 \\
\hline T2-1 & SHS & 6060-Т66 & 48.2 & 1.1 & 268 & 13.1 & 12.3 & 1.07 \\
\hline T7-1 & SHS & 6060-T66 & 48.2 & 1.1 & 289 & 10.7 & 10.6 & 1.01 \\
\hline T1-1 & SHS & 6060-T66 & 48.2 & 1.1 & 287 & 11.9 & 10.7 & 1.11 \\
\hline $1-08$ & SHS & 6060-Т66 & 47.6 & 0.8 & 20 & 12.0 & 13.9 & 0.86 \\
\hline $2-08$ & SHS & 6060-T66 & 47.6 & 0.8 & 20 & 11.4 & 13.3 & 0.86 \\
\hline TA7 & AS & 6060-Т66 & 50 & 2 & 20 & 19.9 & 22.9 & 0.87 \\
\hline TA11 & AS & 6060-Т66 & 50 & 2 & 171 & 16.8 & 18.6 & 0.90 \\
\hline TA4 & AS & 6060-Т66 & 50 & 2 & 267 & 8.4 & 9.0 & 0.94 \\
\hline TA6 & AS & 6060-Т66 & 50 & 2 & 299 & 7.1 & 7.7 & 0.92 \\
\hline O6 & SHS & 5083-H111 & 50 & 1 & 20 & 19.8 & 20.8 & 0.95 \\
\hline O9 & SHS & 5083-H111 & 50 & 1 & 178 & 17.9 & 16.3 & 1.10 \\
\hline $\mathrm{O} 4$ & SHS & 5083-H111 & 50 & 1 & 267 & 12.0 & 11.4 & 1.05 \\
\hline $\mathrm{O} 3$ & SHS & 5083-H111 & 50 & 1 & 323 & 8.2 & 7.9 & 1.04 \\
\hline O5 & SHS & 5083-H111 & 50 & 1 & 345 & 6.2 & 5.6 & 1.11 \\
\hline OA3 & AS & 5083-H111 & 50 & 1 & 20 & 5.1 & 5.9 & 0.86 \\
\hline OA4 & AS & 5083-H111 & 50 & 1 & 167 & 4.9 & 4.8 & 1.02 \\
\hline OA5 & AS & 5083-H111 & 50 & 1 & 270 & 2.9 & 3.2 & 0.92 \\
\hline OA6 & AS & 5083-H111 & 50 & 1 & 325 & 1.9 & 1.9 & 1.00 \\
\hline \multirow[t]{2}{*}{ OA7 } & AS & 5083-H111 & 50 & 1 & 339 & 1.5 & 1.6 & 0.94 \\
\hline & & & & & & & $\begin{array}{r}\text { Mean, } P \\
\text { CoV, } V\end{array}$ & $\begin{array}{c}0.99 \\
0.083\end{array}$ \\
\hline
\end{tabular}


Table. 2. Material properties of aluminium alloy 6061-T6 at elevated temperatures

\begin{tabular}{|c|c|c|c|c|c|c|c|c|}
\hline \multirow[b]{2}{*}{$\begin{array}{l}\text { Temperature } \\
\left({ }^{\circ} \mathrm{C}\right)\end{array}$} & \multicolumn{3}{|c|}{ Su and Young [6] } & \multicolumn{3}{|c|}{ AA [1] } & \multicolumn{2}{|c|}{ EC9 [4] } \\
\hline & $\begin{array}{c}E_{T} \\
(\mathrm{GPa}) \\
\end{array}$ & $\begin{array}{c}f_{y, T} \\
(\mathrm{MPa})\end{array}$ & $\begin{array}{c}f_{u, T} \\
(\mathrm{MPa})\end{array}$ & $\begin{array}{c}E_{T} \\
(\mathrm{GPa}) \\
\end{array}$ & $\begin{array}{c}f_{y, T} \\
(\mathrm{MPa})\end{array}$ & $\begin{array}{c}f_{u, T} \\
(\mathrm{MPa})\end{array}$ & $\begin{array}{r}E_{T} \\
(\mathrm{GPa}) \\
\end{array}$ & $\begin{array}{c}f_{y, T} \\
(\mathrm{MPa})\end{array}$ \\
\hline 24 & 69.5 & 199.9 & 232.3 & 69.5 & 199.9 & 232.3 & 70.0 & 199.9 \\
\hline 100 & 64.0 & 195.2 & 225.1 & 66.7 & 189.9 & 204.8 & 69.3 & 189.9 \\
\hline 200 & 63.4 & 176.9 & 197.8 & 60.8 & 153.8 & 136.3 & 67.9 & 157.9 \\
\hline 250 & 59.4 & 176.0 & 190.8 & 56.6 & 92.8 & 85.2 & 65.1 & 109.9 \\
\hline 300 & 58.5 & 181.0 & 189.1 & 50.1 & 51.4 & 48.6 & 60.2 & 62.0 \\
\hline 350 & 55.1 & 164.0 & 169.6 & 42.4 & 25.1 & 21.3 & 54.6 & 20.0 \\
\hline 400 & 52.1 & 139.0 & 145.9 & 32.2 & 13.2 & 9.6 & 47.6 & 15.0 \\
\hline 450 & 54.2 & 105.1 & 108.4 & 20.5 & 8.8 & 4.6 & 37.8 & 10.0 \\
\hline 500 & 43.1 & 80.7 & 85.1 & 8.7 & 3.6 & 1.5 & 28.0 & 5.0 \\
\hline 600 & 15.7 & 17.5 & 20.6 & - & - & - & - & - \\
\hline
\end{tabular}


Table. 3. Material properties of aluminium alloy 6063-T5 at elevated temperatures

\begin{tabular}{|c|c|c|c|c|c|c|c|c|}
\hline \multirow[b]{2}{*}{$\begin{array}{c}\text { Temperature } \\
\left({ }^{\circ} \mathrm{C}\right)\end{array}$} & \multicolumn{3}{|c|}{ Su and Young [6] } & \multicolumn{3}{|c|}{ AA [1] } & \multicolumn{2}{|c|}{ EC9 [4] } \\
\hline & $\begin{array}{r}E_{T} \\
(\mathrm{GPa}) \\
\end{array}$ & $\begin{array}{r}f_{y, T} \\
(\mathrm{MPa})\end{array}$ & $\begin{array}{r}f_{u, T} \\
(\mathrm{MPa})\end{array}$ & $\begin{array}{c}E_{T} \\
(\mathrm{GPa}) \\
\end{array}$ & $\begin{array}{c}f_{y, T} \\
(\mathrm{MPa})\end{array}$ & $\begin{array}{c}f_{u, T} \\
(\mathrm{MPa})\end{array}$ & $\begin{array}{r}E_{T} \\
(\mathrm{GPa}) \\
\end{array}$ & $\begin{array}{c}f_{y, T} \\
(\mathrm{MPa})\end{array}$ \\
\hline 24 & 65.6 & 186.6 & 226.8 & 65.6 & 186.6 & 226.8 & 70.0 & 186.6 \\
\hline 100 & 63.4 & 183.7 & 217.6 & 63.0 & 173.5 & 198.0 & 69.3 & 171.7 \\
\hline 200 & 56.1 & 163.1 & 183.4 & 57.4 & 132.7 & 121.2 & 67.9 & 141.8 \\
\hline 250 & 54.2 & 147.1 & 159.3 & 53.4 & 76.5 & 67.4 & 65.1 & 91.4 \\
\hline 300 & 51.7 & 131.2 & 138.5 & 47.3 & 45.8 & 34.8 & 60.2 & 54.1 \\
\hline 350 & 47.3 & 111.9 & 114.2 & 40.0 & 23.5 & 14.1 & 54.6 & 26.1 \\
\hline 400 & 33.7 & 67.9 & 71 & 30.4 & 12.3 & 4.7 & 47.6 & 19.6 \\
\hline 450 & 44.0 & 47 & 50.6 & 19.4 & 7.9 & 2.1 & 37.8 & 13.1 \\
\hline 500 & 34.1 & 18.6 & 19.1 & 8.2 & 3.4 & 0.3 & 28.0 & 6.5 \\
\hline 600 & 28.9 & 7.3 & 7.6 & - & - & - & - & - \\
\hline
\end{tabular}


Table. 4. Dimensions of cross-sections in parametric study

\begin{tabular}{ccccc}
\hline Series & $\begin{array}{c}H \\
(\mathrm{~mm})\end{array}$ & $\begin{array}{c}B \\
(\mathrm{~mm})\end{array}$ & $\begin{array}{c}B_{l} \\
(\mathrm{~mm})\end{array}$ & $\begin{array}{c}t \\
(\mathrm{~mm})\end{array}$ \\
\hline P1 & 120 & 60 & - & 8 \\
P2 & 120 & 60 & - & 6 \\
P3 & 120 & 60 & - & 4 \\
L1 & 120 & 60 & 15 & 8 \\
L2 & 120 & 60 & 15 & 6 \\
L3 & 120 & 60 & 15 & 4 \\
\hline
\end{tabular}


Table.5. Numerical ultimate strengths of FE model at elevated temperatures of Series H-P

\begin{tabular}{|c|c|c|c|c|c|c|c|c|}
\hline $\begin{array}{l}\text { Specimen } \\
(H / t=15, B / t=8)\end{array}$ & $\begin{array}{l}\text { Classification } \\
\text { of } \\
\text { cross-sections }\end{array}$ & $P_{\mathrm{FE}}(\mathrm{kN})$ & $\begin{array}{l}\text { Specimen } \\
(H / t=20, B / t=10)\end{array}$ & $\begin{array}{l}\text { Classificatior } \\
\text { of } \\
\text { cross-section }\end{array}$ & $P_{\mathrm{FE}}(\mathrm{kN})$ & $\begin{array}{l}\text { Specimen } \\
(H / t=30, B / t=15)\end{array}$ & $\begin{array}{l}\text { Classification } \\
\text { of } \\
\text { cross-sections }\end{array}$ & $P_{\mathrm{FE}}(\mathrm{kN})$ \\
\hline H-P1-L360-T24 & Class2 & 384.1 & H-P2-L360-T24 & Class3 & 274.2 & H-P3-L360-T24 & Class4 & 150.0 \\
\hline H-P1-L360-T100 & Class2 & 375.2 & H-P2-L360-T100 & Class3 & 266.0 & H-P3-L360-T100 & Class4 & 143.0 \\
\hline H-P1-L360-T200 & Class2 & 340.3 & H-P2-L360-T200 & Class2 & 242.6 & H-P3-L360-T200 & Class 4 & 134.4 \\
\hline H-P1-L360-T250 & Class2 & 337.6 & H-P2-L360-T250 & Class2 & 241.4 & H-P3-L360-T250 & Class 4 & 129.8 \\
\hline H-P1-L360-T300 & Class2 & 345.7 & H-P2-L360-T300 & Class3 & 247.9 & H-P3-L360-T300 & Class4 & 132.2 \\
\hline H-P1-L360-T350 & Class2 & 312.2 & H-P2-L360-T350 & Class2 & 225.2 & H-P3-L360-T350 & Class 4 & 120.8 \\
\hline H-P1-L360-T400 & Class1 & 266.6 & H-P2-L360-T400 & Class2 & 192.3 & H-P3-L360-T400 & Class3 & 105.9 \\
\hline H-P1-L360-T450 & Class1 & 201.2 & H-P2-L360-T450 & Class2 & 147.6 & H-P3-L360-T450 & Class3 & 87.8 \\
\hline H-P1-L360-T500 & Class1 & 156.8 & H-P2-L360-T500 & Class 1 & 113.0 & H-P3-L360-T500 & Class3 & 69.5 \\
\hline H-P1-L360-T600 & Class1 & 34.1 & H-P2-L360-T600 & Class1 & 25.0 & H-P3-L360-T600 & Class1 & 15.3 \\
\hline H-P1-L1000-T24 & Class2 & 356.0 & H-P2-L1000-T24 & Class3 & 266.6 & H-P3-L1000-T24 & Class 4 & 142.4 \\
\hline H-P1-L1000-T100 & Class2 & 347.4 & H-P2-L1000-T100 & Class3 & 260.1 & H-P3-L1000-T100 & Class 4 & 133.9 \\
\hline H-P1-L1000-T200 & Class2 & 315.7 & H-P2-L1000-T200 & Class2 & 236.4 & H-P3-L1000-T200 & Class4 & 127.6 \\
\hline H-P1-L1000-T250 & Class2 & 315.6 & H-P2-L1000-T250 & Class2 & 236.3 & H-P3-L1000-T250 & Class4 & 121.6 \\
\hline H-P1-L1000-T300 & Class2 & 325.0 & H-P2-L1000-T300 & Class3 & 243.5 & H-P3-L1000-T300 & Class4 & 123.2 \\
\hline H-P1-L1000-T350 & Class2 & 295.8 & H-P2-L1000-T350 & Class2 & 221.6 & H-P3-L1000-T350 & Class4 & 112.5 \\
\hline H-P1-L1000-T400 & Class1 & 252.4 & H-P2-L1000-T400 & Class2 & 189.0 & H-P3-L1000-T400 & Class3 & 99.8 \\
\hline H-P1-L1000-T450 & Class 1 & 191.4 & H-P2-L1000-T450 & Class2 & 143.4 & H-P3-L1000-T450 & Class3 & 86.2 \\
\hline H-P1-L1000-T500 & Class1 & 145.8 & H-P2-L1000-T500 & Class1 & 109.2 & H-P3-L1000-T500 & Class3 & 69.5 \\
\hline H-P1-L1000-T600 & Class1 & 31.8 & H-P2-L1000-T600 & Class1 & 23.8 & H-P3-L1000-T600 & Class1 & 15.4 \\
\hline H-P1-L2000-T24 & Class2 & 261.4 & H-P2-L2000-T24 & Class3 & 195.7 & H-P3-L2000-T24 & Class4 & 129.1 \\
\hline H-P1-L2000-T100 & Class2 & 244.1 & H-P2-L2000-T100 & Class3 & 182.6 & H-P3-L2000-T100 & Class4 & 119.8 \\
\hline H-P1-L2000-T200 & Class2 & 231.5 & H-P2-L2000-T200 & Class2 & 173.2 & H-P3-L2000-T200 & Class4 & 114.2 \\
\hline H-P1-L2000-T250 & Class2 & 218.6 & H-P2-L2000-T250 & Class2 & 163.4 & H-P3-L2000-T250 & Class 4 & 107.0 \\
\hline H-P1-L2000-T300 & Class2 & 225.8 & H-P2-L2000-T300 & Class3 & 168.9 & H-P3-L2000-T300 & Class4 & 110.5 \\
\hline H-P1-L2000-T350 & Class2 & 200.1 & H-P2-L2000-T350 & Class2 & 149.7 & H-P3-L2000-T350 & Class4 & 97.8 \\
\hline H-P1-L2000-T400 & Class1 & 174.0 & H-P2-L2000-T400 & Class2 & 130.2 & H-P3-L2000-T400 & Class3 & 85.6 \\
\hline H-P1-L2000-T450 & Class1 & 148.6 & H-P2-L2000-T450 & Class2 & 111.2 & H-P3-L2000-T450 & Class3 & 74.0 \\
\hline H-P1-L2000-T500 & Class1 & 118.1 & H-P2-L2000-T500 & Class1 & 88.5 & H-P3-L2000-T500 & Class3 & 58.9 \\
\hline H-P1-L2000-T600 & Class1 & 26.6 & H-P2-L2000-T600 & Class1 & 19.9 & H-P3-L2000-T600 & Class1 & 13.3 \\
\hline
\end{tabular}


Table.6. Numerical ultimate strengths of FE model at elevated temperatures of Series H-L

\begin{tabular}{|c|c|c|c|c|c|c|c|c|}
\hline $\begin{array}{l}\text { Specimen } \\
(\mathrm{H} / \mathrm{t}=15, \mathrm{~B} / \mathrm{t}=8)\end{array}$ & $\begin{array}{c}\text { Classification } \\
\text { of } \\
\text { cross-sections }\end{array}$ & $P_{\mathrm{FE}}(\mathrm{kN})$ & $\begin{array}{l}\text { Specimen } \\
(\mathrm{H} / \mathrm{t}=20, \mathrm{~B} / \mathrm{t}=10)\end{array}$ & $\begin{array}{l}\text { Classificatic } \\
\text { of } \\
\text { cross-sectio }\end{array}$ & $P_{\mathrm{FE}}(\mathrm{kN})$ & $\begin{array}{l}\text { Specimen } \\
(\mathrm{H} / \mathrm{t}=30, \mathrm{~B} / \mathrm{t}=15)\end{array}$ & $\begin{array}{l}\text { Classification } \\
\text { of } \\
\text { cross-sections }\end{array}$ & $P_{\mathrm{FE}}(\mathrm{kN})$ \\
\hline H-L1-L360-T24 & Class2 & 430.5 & H-L2-L360-T24 & Class3 & 312.9 & H-L3-L360-T24 & Class 4 & 191.4 \\
\hline H-L1-L360-T100 & Class2 & 420.6 & H-L2-L360-T100 & Class3 & 304.3 & H-L3-L360-T100 & Class 4 & 184.4 \\
\hline H-L1-L360-T200 & Class2 & 381.1 & H-L2-L360-T200 & Class2 & 276.2 & H-L3-L360-T200 & Class 4 & 170.5 \\
\hline H-L1-L360-T250 & Class2 & 378.6 & H-L2-L360-T250 & Class2 & 275.6 & H-L3-L360-T250 & Class4 & 167.5 \\
\hline H-L1-L360-T300 & Class2 & 387.7 & H-L2-L360-T300 & Class3 & 283.4 & H-L3-L360-T300 & Class4 & 171.9 \\
\hline H-L1-L360-T350 & Class2 & 350.5 & H-L2-L360-T350 & Class2 & 256.8 & H-L3-L360-T350 & Class 4 & 156.3 \\
\hline H-L1-L360-T400 & Class 1 & 298.7 & H-L2-L360-T400 & Class2 & 218.8 & H-L3-L360-T400 & Class3 & 134.7 \\
\hline H-L1-L360-T450 & Class 1 & 225.4 & H-L2-L360-T450 & Class2 & 166.2 & H-L3-L360-T450 & Class3 & 105.5 \\
\hline H-L1-L360-T500 & Class 1 & 175.6 & H-L2-L360-T500 & Class 1 & 127.5 & H-L3-L360-T500 & Class3 & 82.0 \\
\hline H-L1-L360-T600 & Class 1 & 38.2 & H-L2-L360-T600 & Class 1 & 28.2 & H-L3-L360-T600 & Class 1 & 17.9 \\
\hline H-L1-L1000-T24 & Class2 & 407.6 & H-L2-L1000-T24 & Class3 & 300.1 & H-L3-L1000-T24 & Class 4 & 188.7 \\
\hline H-L1-L1000-T100 & Class2 & 396.8 & H-L2-L1000-T100 & Class3 & 292.1 & H-L3-L1000-T100 & Class4 & 181.7 \\
\hline H-L1-L1000-T200 & Class2 & 360.7 & H-L2-L1000-T200 & Class2 & 266.2 & H-L3-L1000-T200 & Class 4 & 168.1 \\
\hline H-L1-L1000-T250 & Class2 & 360.3 & H-L2-L1000-T250 & Class2 & 265.5 & H-L3-L1000-T250 & Class 4 & 165.3 \\
\hline H-L1-L1000-T300 & Class2 & 370.9 & H-L2-L1000-T300 & Class3 & 273.3 & H-L3-L1000-T300 & Class 4 & 169.1 \\
\hline H-L1-L1000-T350 & Class2 & 337.2 & H-L2-L1000-T350 & Class2 & 248.8 & H-L3-L1000-T350 & Class 4 & 155.2 \\
\hline H-L1-L1000-T400 & Class 1 & 287.8 & H-L2-L1000-T400 & Class2 & 212.7 & H-L3-L1000-T400 & Class 3 & 134.2 \\
\hline H-L1-L1000-T450 & Class 1 & 219.1 & H-L2-L1000-T450 & Class2 & 162.3 & H-L3-L1000-T450 & Class3 & 105.2 \\
\hline H-L1-L1000-T500 & Class 1 & 166.9 & H-L2-L1000-T500 & Class 1 & 123.9 & H-L3-L1000-T500 & Class 3 & 81.2 \\
\hline H-L1-L1000-T600 & Class 1 & 36.8 & H-L2-L1000-T600 & Class 1 & 27.2 & H-L3-L1000-T600 & Class 1 & 17.7 \\
\hline H-L1-L2000-T24 & Class2 & 326.9 & H-L2-L2000-T24 & Class3 & 244.2 & H-L3-L2000-T24 & Class4 & 160.1 \\
\hline H-L1-L2000-T100 & Class2 & 312.3 & H-L2-L2000-T100 & Class 3 & 233.3 & H-L3-L2000-T100 & Class 4 & 152.2 \\
\hline H-L1-L2000-T200 & Class2 & 292.0 & H-L2-L2000-T200 & Class2 & 218.1 & H-L3-L2000-T200 & Class 4 & 142.8 \\
\hline H-L1-L2000-T250 & Class2 & 282.5 & H-L2-L2000-T250 & Class2 & 210.7 & H-L3-L2000-T250 & Class 4 & 137.2 \\
\hline H-L1-L2000-T300 & Class2 & 288.1 & H-L2-L2000-T300 & Class 3 & 214.8 & H-L3-L2000-T300 & Class4 & 140.2 \\
\hline H-L1-L2000-T350 & Class2 & 263.7 & H-L2-L2000-T350 & Class2 & 196.7 & H-L3-L2000-T350 & Class 4 & 127.8 \\
\hline H-L1-L2000-T400 & Class 1 & 230.7 & H-L2-L2000-T400 & Class2 & 172.2 & H-L3-L2000-T400 & Class3 & 112.3 \\
\hline H-L1-L2000-T450 & Class 1 & 188.3 & H-L2-L2000-T450 & Class2 & 140.8 & H-L3-L2000-T450 & Class3 & 92.8 \\
\hline H-L1-L2000-T500 & Class 1 & 145.2 & H-L2-L2000-T500 & Class 1 & 108.7 & H-L3-L2000-T500 & Class3 & 71.9 \\
\hline H-L1-L2000-T600 & Class 1 & 31.9 & H-L2-L2000-T600 & Class 1 & 23.9 & H-L3-L2000-T600 & Class 1 & 15.8 \\
\hline
\end{tabular}


Table.7. Numerical ultimate strengths of FE model at elevated temperatures of Series N-P

\begin{tabular}{|c|c|c|c|c|c|c|c|c|}
\hline $\begin{array}{l}\text { Specimen } \\
(H / t=15, B / t=8)\end{array}$ & $\begin{array}{l}\text { Classification } \\
\text { of } \\
\text { cross-sections }\end{array}$ & $P_{\mathrm{FE}}(\mathrm{kN})$ & $\begin{array}{l}\text { Specimen } \\
(H / t=20, B / t=10)\end{array}$ & $\begin{array}{l}\text { Classification } \\
\text { of } \\
\text { cross-sections }\end{array}$ & $P_{\mathrm{FE}}(\mathrm{kN})$ & $\begin{array}{l}\text { Specimen } \\
(H / t=30, B / t=15)\end{array}$ & $\begin{array}{l}\text { Classification } \\
\text { of } \\
\text { cross-sections }\end{array}$ & $P_{\mathrm{FE}}(\mathrm{kN})$ \\
\hline N-P1-L360-T24 & Class1 & 364.9 & N-P2-L360-T24 & Class3 & 256.6 & N-P3-L360-T24 & Class 4 & 139.1 \\
\hline N-P1-L360-T100 & Class1 & 357.8 & N-P2-L360-T100 & Class3 & 252.9 & N-P3-L360-T100 & Class4 & 136.6 \\
\hline N-P1-L360-T200 & Class1 & 315.5 & N-P2-L360-T200 & Class2 & 223.0 & N-P3-L360-T200 & Class4 & 120.6 \\
\hline N-P1-L360-T250 & Class1 & 283.5 & N-P2-L360-T250 & Class2 & 202.9 & N-P3-L360-T250 & Class4 & 111.4 \\
\hline N-P1-L360-T300 & Class1 & 252.9 & N-P2-L360-T300 & Class2 & 182.0 & N-P3-L360-T300 & Class3 & 101.4 \\
\hline N-P1-L360-T350 & Class1 & 211.8 & N-P2-L360-T350 & Class1 & 155.0 & N-P3-L360-T350 & Class3 & 87.8 \\
\hline N-P1-L360-T400 & Class1 & 132.3 & N-P2-L360-T400 & Class1 & 95.4 & N-P3-L360-T400 & Class2 & 56.4 \\
\hline N-P1-L360-T450 & Class1 & 93.9 & N-P2-L360-T450 & Class1 & 68.3 & N-P3-L360-T450 & Class1 & 41.7 \\
\hline N-P1-L360-T500 & Class 1 & 35.8 & N-P2-L360-T500 & Class1 & 26.7 & N-P3-L360-T500 & Class1 & 17.4 \\
\hline N-P1-L360-T600 & Class1 & 14.2 & N-P2-L360-T600 & Class1 & 10.6 & N-P3-L360-T600 & Class1 & 7.0 \\
\hline N-P1-L1000-T24 & Class1 & 333.0 & N-P2-L1000-T24 & Class3 & 249.3 & N-P3-L1000-T24 & Class4 & 131.1 \\
\hline N-P1-L1000-T100 & Class1 & 329.1 & N-P2-L1000-T100 & Class3 & 246.5 & N-P3-L1000-T100 & Class 4 & 128.3 \\
\hline N-P1-L1000-T200 & Class1 & 290.3 & N-P2-L1000-T200 & Class2 & 217.4 & N-P3-L1000-T200 & Class 4 & 113.3 \\
\hline N-P1-L1000-T250 & Class1 & 263.8 & N-P2-L1000-T250 & Class2 & 197.6 & N-P3-L1000-T250 & Class 4 & 105.7 \\
\hline N-P1-L1000-T300 & Class1 & 236.1 & N-P2-L1000-T300 & Class2 & 176.9 & N-P3-L1000-T300 & Class3 & 96.7 \\
\hline N-P1-L1000-T350 & Class1 & 199.2 & N-P2-L1000-T350 & Class1 & 149.3 & N-P3-L1000-T350 & Class3 & 84.9 \\
\hline N-P1-L1000-T400 & Class 1 & 122.1 & N-P2-L1000-T400 & Class1 & 91.5 & N-P3-L1000-T400 & Class2 & 55.6 \\
\hline N-P1-L1000-T450 & Class1 & 86.2 & N-P2-L1000-T450 & Class1 & 64.6 & N-P3-L1000-T450 & Class1 & 42.3 \\
\hline N-P1-L1000-T500 & Class1 & 34.5 & N-P2-L1000-T500 & Class1 & 25.9 & N-P3-L1000-T500 & Class1 & 17.2 \\
\hline N-P1-L1000-T600 & Class1 & 13.6 & N-P2-L1000-T600 & Class 1 & 10.3 & N-P3-L1000-T600 & Class1 & 6.8 \\
\hline N-P1-L2000-T24 & Class1 & 235.3 & N-P2-L2000-T24 & Class3 & 176.0 & N-P3-L2000-T24 & Class4 & 115.9 \\
\hline N-P1-L2000-T100 & Class1 & 231.3 & N-P2-L2000-T100 & Class3 & 173.0 & N-P3-L2000-T100 & Class 4 & 113.7 \\
\hline N-P1-L2000-T200 & Class1 & 204.0 & N-P2-L2000-T200 & Class2 & 152.6 & N-P3-L2000-T200 & Class4 & 100.3 \\
\hline N-P1-L2000-T250 & Class1 & 187.7 & N-P2-L2000-T250 & Class2 & 144.8 & N-P3-L2000-T250 & Class 4 & 92.6 \\
\hline N-P1-L2000-T300 & Class1 & 169.8 & N-P2-L2000-T300 & Class2 & 127.0 & N-P3-L2000-T300 & Class3 & 84.0 \\
\hline N-P1-L2000-T350 & Class1 & 146.8 & N-P2-L2000-T350 & Class1 & 109.8 & N-P3-L2000-T350 & Class3 & 72.8 \\
\hline N-P1-L2000-T400 & Class1 & 97.9 & N-P2-L2000-T400 & Class1 & 73.3 & N-P3-L2000-T400 & Class2 & 48.7 \\
\hline N-P1-L2000-T450 & Class1 & 72.0 & N-P2-L2000-T450 & Class1 & 54.0 & N-P3-L2000-T450 & Class1 & 35.9 \\
\hline N-P1-L2000-T500 & Class1 & 31.2 & N-P2-L2000-T500 & Class1 & 23.3 & N-P3-L2000-T500 & Class1 & 15.6 \\
\hline N-P1-L2000-T600 & Class1 & 13.3 & N-P2-L2000-T600 & Class1 & 10.0 & N-P3-L2000-T600 & Class1 & 6.6 \\
\hline
\end{tabular}


Table.8. Numerical ultimate strengths of FE model at elevated temperatures of Series N-L

\begin{tabular}{|c|c|c|c|c|c|c|c|c|}
\hline $\begin{array}{l}\text { Specimen } \\
(H / t=15, B / t=8)\end{array}$ & $\begin{array}{l}\text { Classification } \\
\text { of } \\
\text { cross-sections }\end{array}$ & $P_{\mathrm{FE}}(\mathrm{kN})$ & $\begin{array}{l}\text { Specimen } \\
(H / t=20, B / t=10)\end{array}$ & $\begin{array}{l}\text { Classification } \\
\text { of } \\
\text { cross-sections }\end{array}$ & $P_{\mathrm{FE}}(\mathrm{kN})$ & $\begin{array}{l}\text { Specimen } \\
(H / t=30, B / t=15)\end{array}$ & $\begin{array}{c}\text { Classification } \\
\text { of } \\
\text { cross-sections }\end{array}$ & $P_{\mathrm{FE}}(\mathrm{kN})$ \\
\hline N-L1-L360-T24 & Class1 & 409.0 & N-L2-L360-T24 & Class3 & 294.4 & N-L3-L360-T24 & Class4 & 178.5 \\
\hline N-L1-L360-T100 & Class1 & 401.0 & N-L2-L360-T100 & Class3 & 289.3 & N-L3-L360-T100 & Class 4 & 175.8 \\
\hline N-L1-L360-T200 & Class1 & 353.5 & N-L2-L360-T200 & Class2 & 255.1 & N-L3-L360-T200 & Class 4 & 155.1 \\
\hline N-L1-L360-T250 & Class1 & 317.7 & N-L2-L360-T250 & Class2 & 231.2 & N-L3-L360-T250 & Class4 & 142.1 \\
\hline N-L1-L360-T300 & Class1 & 283.2 & N-L2-L360-T300 & Class2 & 207.1 & N-L3-L360-T300 & Class3 & 127.9 \\
\hline N-L1-L360-T350 & Class1 & 239.5 & N-L2-L360-T350 & Class1 & 176.0 & N-L3-L360-T350 & Class3 & 110.1 \\
\hline N-L1-L360-T400 & Class1 & 148.0 & N-L2-L360-T400 & Class1 & 108.1 & N-L3-L360-T400 & Class2 & 67.5 \\
\hline N-L1-L360-T450 & Class1 & 105.0 & N-L2-L360-T450 & Class1 & 77.0 & N-L3-L360-T450 & Class 1 & 48.7 \\
\hline N-L1-L360-T500 & Class1 & 40.2 & N-L2-L360-T500 & Class1 & 30.0 & N-L3-L360-T500 & Class 1 & 19.7 \\
\hline N-L1-L360-T600 & Class1 & 15.9 & N-L2-L360-T600 & Class1 & 11.9 & N-L3-L360-T600 & Class 1 & 7.9 \\
\hline N-L1-L1000-T24 & Class1 & 381.6 & N-L2-L1000-T24 & Class3 & 280.5 & N-L3-L1000-T24 & Class 4 & 176.0 \\
\hline N-L1-L1000-T100 & Class1 & 376.5 & N-L2-L1000-T100 & Class3 & 277.2 & N-L3-L1000-T100 & Class 4 & 173.4 \\
\hline N-L1-L1000-T200 & Class1 & 332.1 & N-L2-L1000-T200 & Class2 & 244.5 & N-L3-L1000-T200 & Class 4 & 153.0 \\
\hline N-L1-L1000-T250 & Class1 & 301.8 & N-L2-L1000-T250 & Class2 & 222.5 & N-L3-L1000-T250 & Class4 & 140.3 \\
\hline N-L1-L1000-T300 & Class1 & 270.6 & N-L2-L1000-T300 & Class2 & 199.4 & N-L3-L1000-T300 & Class3 & 126.4 \\
\hline N-L1-L1000-T350 & Class1 & 230.1 & N-L2-L1000-T350 & Class1 & 170.7 & N-L3-L1000-T350 & Class3 & 109.0 \\
\hline N-L1-L1000-T400 & Class1 & 140.6 & N-L2-L1000-T400 & Class1 & 103.8 & N-L3-L1000-T400 & Class2 & 67.1 \\
\hline N-L1-L1000-T450 & Class1 & 100.3 & N-L2-L1000-T450 & Class1 & 73.9 & N-L3-L1000-T450 & Class 1 & 48.0 \\
\hline N-L1-L1000-T500 & Class1 & 39.6 & N-L2-L1000-T500 & Class1 & 29.6 & N-L3-L1000-T500 & Class 1 & 19.5 \\
\hline N-L1-L1000-T600 & Class 1 & 15.6 & N-L2-L1000-T600 & Class1 & 11.7 & N-L3-L1000-T600 & Class 1 & 7.7 \\
\hline N-L1-L2000-T24 & Class1 & 300.3 & N-L2-L2000-T24 & Class3 & 224.2 & N-L3-L2000-T24 & Class 4 & 146.6 \\
\hline N-L1-L2000-T100 & Class1 & 295.3 & N-L2-L2000-T100 & Class3 & 220.5 & N-L3-L2000-T100 & Class4 & 144.0 \\
\hline N-L1-L2000-T200 & Class 1 & 260.7 & N-L2-L2000-T200 & Class2 & 194.6 & N-L3-L2000-T200 & Class 4 & 127.2 \\
\hline N-L1-L2000-T250 & Class1 & 240.3 & N-L2-L2000-T250 & Class2 & 179.4 & N-L3-L2000-T250 & Class 4 & 117.3 \\
\hline N-L1-L2000-T300 & Class1 & 217.0 & N-L2-L2000-T300 & Class2 & 162.0 & N-L3-L2000-T300 & Class3 & 106.1 \\
\hline N-L1-L2000-T350 & Class1 & 189.2 & N-L2-L2000-T350 & Class 1 & 141.4 & N-L3-L2000-T350 & Class3 & 92.7 \\
\hline N-L1-L2000-T400 & Class1 & 119.3 & N-L2-L2000-T400 & Class 1 & 89.3 & N-L3-L2000-T400 & Class2 & 58.9 \\
\hline N-L1-L2000-T450 & Class 1 & 85.7 & N-L2-L2000-T450 & Class 1 & 64.1 & N-L3-L2000-T450 & Class 1 & 42.6 \\
\hline N-L1-L2000-T500 & Class1 & 36.2 & N-L2-L2000-T500 & Class 1 & 27.1 & N-L3-L2000-T500 & Class1 & 18.0 \\
\hline N-L1-L2000-T600 & Class1 & 15.0 & N-L2-L2000-T600 & Class1 & 11.3 & N-L3-L2000-T600 & Class1 & 7.5 \\
\hline
\end{tabular}


Table. 9. Comparisons between numerical results and design predictions for Series H-P

\begin{tabular}{lccccc}
\hline \multirow{2}{*}{$\begin{array}{l}\text { Specimens } \\
\text { Number of }\end{array}$} & \multicolumn{5}{c}{ Comparisons } \\
\cline { 2 - 5 } specimens: 90) & $\frac{P_{F E}}{P_{A A-1}}$ & $\frac{P_{F E}}{P_{A A-2}}$ & $\frac{P_{F E}}{P_{A S / N A S-1}}$ & $\frac{P_{F E}}{P_{E C 9-1}}$ & $\frac{P_{F E}}{P_{E C 9-2}}$ \\
\hline Mean, $P_{m}$ & 1.00 & 6.26 & 1.04 & 1.12 & 5.48 \\
CoV, $V_{P}$ & 0.070 & 1.067 & 0.104 & 0.060 & 0.907 \\
Resistance factor, $\phi$ & 0.85 & 0.85 & 0.85 & 0.91 & 0.91 \\
Reliability index, $\beta$ & 2.87 & 2.27 & 2.67 & 2.96 & 2.39 \\
\hline
\end{tabular}


Table. 10. Comparisons between numerical results and design predictions for Series H-L

\begin{tabular}{lccccc}
\hline Specimens & \multicolumn{5}{c}{ Comparisons } \\
\cline { 2 - 5 } (Number of & $P_{F E}$ & $\frac{P_{F E}}{P_{A A-2}}$ & $\frac{P_{F E}}{P_{A S / N A S-1}}$ & $\frac{P_{F E}}{P_{E C 9-1}}$ & $\frac{P_{F E}}{P_{E C 9-2}}$ \\
\hline Mecimens: 90) & 1.07 & 6.86 & 1.12 & 1.26 & 6.05 \\
CoV, $V_{P}$ & 0.048 & 1.049 & 0.082 & 0.089 & 0.885 \\
Resistance factor, $\phi$ & 0.85 & 0.85 & 0.85 & 0.91 & 0.91 \\
Reliability index, $\beta$ & 3.24 & 2.39 & 3.09 & 3.30 & 2.56 \\
\hline
\end{tabular}



Table. 11. Comparisons between numerical results and design predictions for Series N-P

\begin{tabular}{lccccc}
\hline \begin{tabular}{l} 
Specimens \\
(Number of \\
\cline { 2 - 5 } specimens: 90)
\end{tabular} & $\frac{P_{F E}}{P_{A A-1}}$ & $\frac{P_{F E}}{P_{A A-2}}$ & $\frac{P_{F E}}{P_{A S / N A S-1}}$ & $\frac{P_{F E}}{P_{E C 9-1}}$ & $\frac{P_{F E}}{P_{E C 9-2}}$ \\
\hline Mean, $P_{m}$ & 1.01 & 3.22 & 1.06 & 1.05 & 2.29 \\
CoV, $V_{P}$ & 0.066 & 0.631 & 0.102 & 0.047 & 0.472 \\
Resistance factor, $\phi$ & 0.85 & 0.85 & 0.85 & 0.91 & 0.91 \\
Reliability index, $\beta$ & 2.94 & 2.72 & 2.76 & 2.70 & 2.64 \\
\hline
\end{tabular}



Table. 12. Comparisons between numerical results and design predictions for Series N-L

\begin{tabular}{lccccc}
\hline $\begin{array}{l}\text { Specimens } \\
\text { (Number of } \\
\text { specimens: 90) }\end{array}$ & $\frac{P_{F E}}{P_{A A-1}}$ & $\frac{P_{F E}}{P_{A A-2}}$ & $\frac{P_{F E}}{P_{A S / N A S-1}}$ & $\frac{P_{F E}}{P_{E C 9-1}}$ & $\frac{P_{F E}}{P_{E C 9-2}}$ \\
\hline Mean, $P_{m}$ & 1.08 & 3.48 & 1.13 & 1.23 & 2.61 \\
CoV, $V_{P}$ & 0.049 & 0.621 & 0.083 & 0.086 & 0.448 \\
Resistance factor, $\phi$ & 0.85 & 0.85 & 0.85 & 0.91 & 0.91 \\
Reliability index, $\beta$ & 3.27 & 2.87 & 3.15 & 3.22 & 3.01 \\
\hline
\end{tabular}

